\section{Istanbul / Türkiye p. $473-487$}

Received: $12 / 12 / 2021$

Accepted: $21 / 12 / 2021$

Published: 01/01/2022

This article has been scanned I iThenticat No plagiarism detected

\title{
CHILD CUSTODY: A RIGHT OR A DUTY \\ (A STUDY OF AN APPROACH TO AMEND ARTICLE 57 OF THE IRAQI PERSONAL STATUS LAW)
}

\author{
Um Kalthum Sabeeh MOHAMME $^{1}$ \\ Saja Hazim MAHMOOD ${ }^{2}$
}

\begin{abstract}
:
The current century has witnessed a revolution in different fields which required some legal rules to be reformulated to adapt with the volume of challenges imposed by the contemporary life on marriage life in general, on the children, which are the most important thing that may result from marriage, and on the importance of caring for their needs. As God has divided the parents' duties in caring for their children throughout the stages of their liv.es. He laid upon the mother the responsibility of caring for children starting from pregnancy, delivery, breastfeeding until infancy. While He, especially, assigned the father the responsibility of what comes after. But sometimes a child may lose one or both parents; and here the question arises about who shall take custody and what is the period required to satisfy that right. Article (57) of Personal Status Law No. (188) for the year 1959 has answered this question with its nine clauses and confirmed the necessity of caring for the child's best interest and prioritizing it over the parents' rights. However, the Iraqi Parliament has adopted an amendment of this Article in its latest proposals under the pretext of being in line with changes of everyday life with the assurance of applying the spirit of Islamic Law. It discussed the transmission of the child's custody from the mother to the father after the age of seven in opposition to the current law that grants the mother this right until the child turns fifteen years of age; it also stipulated that the mother shall not get married in order to attain custody over the child which is regarded as a Statutory Offence represented in forcing the mother not to get married during which she holds custody over the child. Meanwhile, it did not stipulate over the father abstinence from marriage in order to attain custody over his children. The amendments have also showcased the entitlement of the grandfather's right in custody rather than the mother in case the father died or didn't fulfill the conditions of custody. By doing so, the rule would deprive the mother from her child upon turning seven years of age without attention being paid to the subsequential feeling of instability such decision causes to the
\end{abstract}

http://dx.doi.org/10.47832/2717-8293.15.34

Prof. Dr. , Mustansiriyah University, Iraq, destructive.98@gmail.com, https:// orcid.org/0000-0002-9453-1157

Researcher, Mustansiriyah University, Iraq, sosohazm95@gmail.com , https:// orcid.org/0000-0003-4833-1784 
child. The parliament should have tried to balance between the child's right of maternal tenderness or paternal security. This is the aim of our research which will shed light on this subject in two scopes, the first of which focuses on educating the people of the right of custody and its period, and the second of which is dedicated to discussion of amendments and making proper recommendation.

Key words: Custody, Custody Period, Mother's Right, Father's Duty, Article 75, Personal Status Law.

\section{مدة حضانة الصغير بين الحق والواجب (دراسة في مقترح تعديل المادة 57 من قانون الأحوال الثخصية العراقي)}

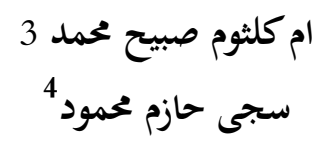

الملخص:

شهد القرن الحالي ثورة في مختلف المجالات مما استوجب إعادة صياغة بعض القواعد القانونية لتتلائم مع حجم التحديات التي فرضتها الحياة المعاصرة على الحياة الزوجية بشكل عام، وعلى أهم ما قد ينتج عنها وهم الأولاد وضرورة رعاية مصالحهم بشكل خاص، فقد قسم الله (جل وعلا) واجبات الوالدين في حفظ الأولاد على مراحل حياقم فخص الأم بمسؤولية الاعتناء بالأطفال بدا من الحمل والولادة والرضاعة والحضانة, بينما خص الأب بتربية الولد بعد ذلك، لكن قد يحدث أحيانا أن يفقد الصغير أحد والديه أو كلاهما، وهنا يثار التساؤل حول من يتولى

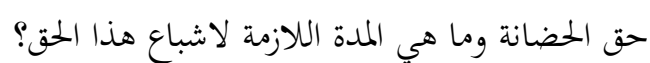

لقد اجابت المادة (57) من قانون الأحوال الشخصية العراقي رقم 188 لسنة 1959 بفقراقا التسع عن هذا السؤال مع التاكيد على وجوب مراعاة مصلحة المضون وتغليبها على حق كل من الأم والاب، إلا أن البرلمان العراقي في طروحاته الاخيرة تبنى تعديلا لنص هذه المادة بحجة الاستجابة لمتغيرات الواقع مع ضمان تطبيق روح

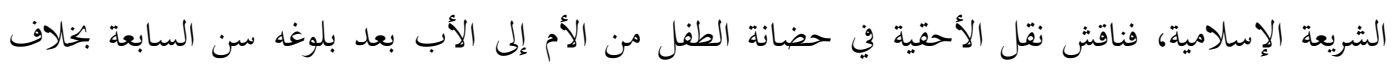
القانون الساري الذي يمنح الأم امكانية بقاء هذا الحق لغاية بلوغ الطفل سن الـ15 عاما كما اشترط عدم زواجها لأخذ الحضانة وهذا يعد مخالفة شرعية تتمثل باجبار الأم على عدم الزواج خلال فترة حضانة الطفل، في حين لم يشترط التعديل في الأب عدم الزواج لنيل حضانة الأبناء، كما نصت التعديلات على أحقية الجد من جهة الأب في الحضانة من الأم، في حال توي الأب أو انتفت لديه شروط الحضانة وبذلك يصبح الأصل حرمان الأم من الأحقية في حضانة أبنائها عندما يتمون السابعة من العمر دون ملاحظة ما يترتب على نفسية الطفل نتيجة عدم

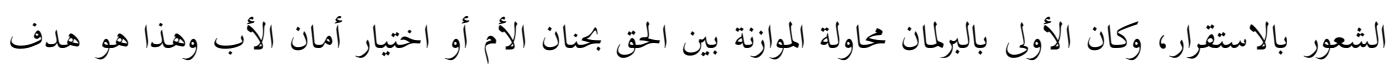
بحثنا الذي سيسلط الضوء على هذا الموضوع في مبحثين نركز الأول على التعريف بكق الحضانة وأحكامها بينما

$$
\text { نخصص الثاني لمناقشة التعديلات وطرح التوصيات الملائمة. }
$$

الكلمات المفتاحية:الحضانة، مدة الحضانة، حق الأم، واجب الاب، المادة 75، قانون الأحوال

الشخصية. 
يعتبر موضوع الحضانة من المواضيع التي نالت حيزاً كبيراً من اهتمام علماء الشريعة والقانون لاها تتعلق بالطفل بالدرجة

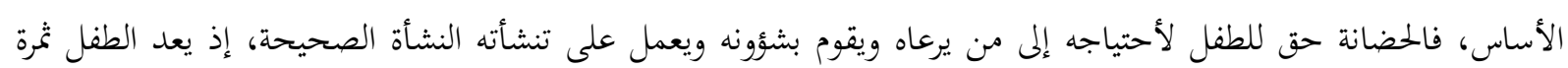

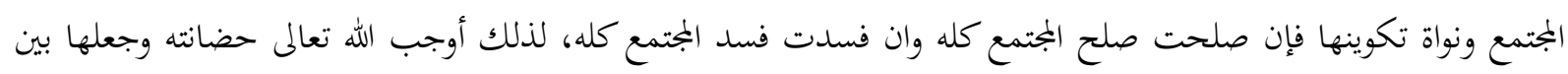

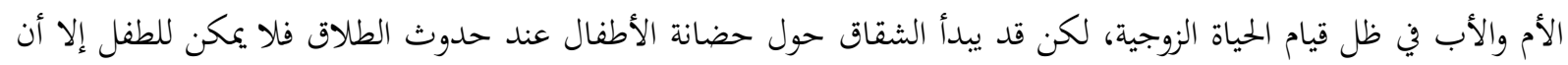

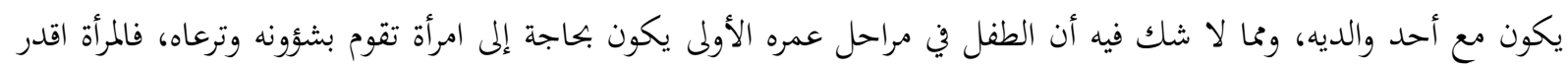

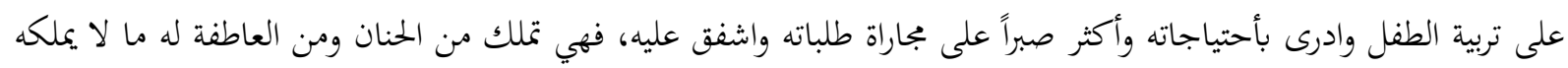

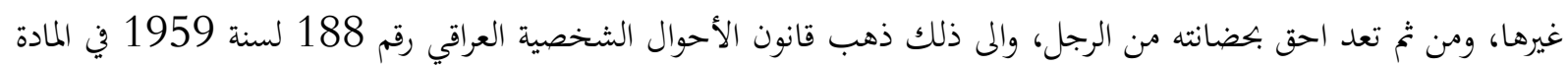

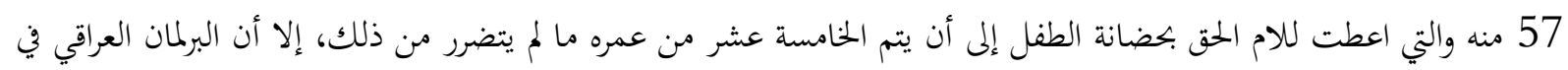

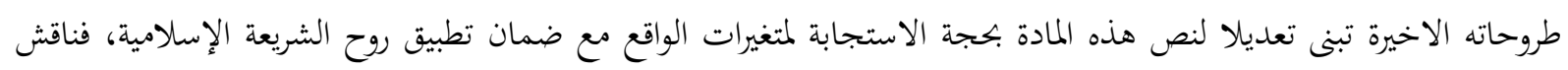

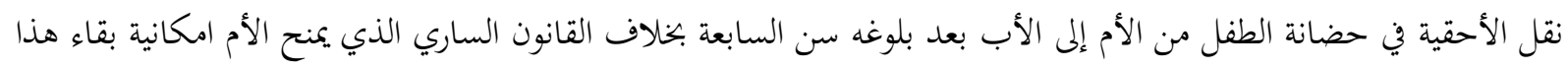

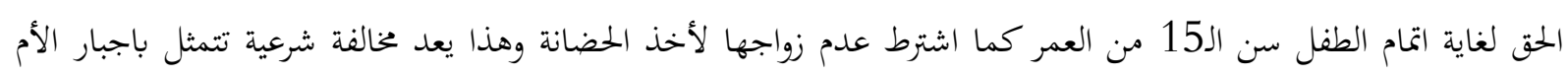

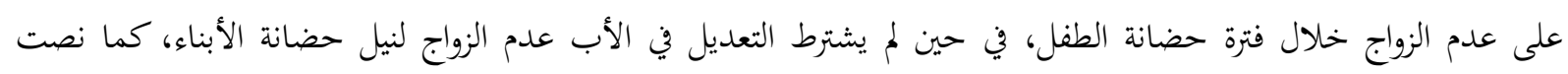

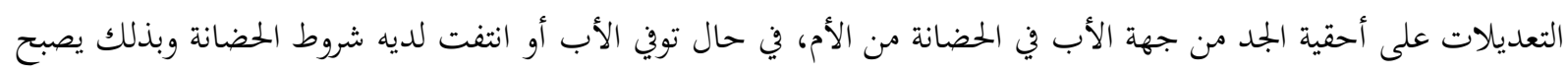

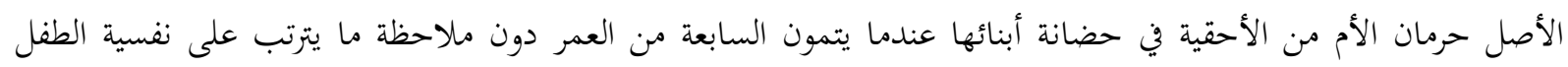

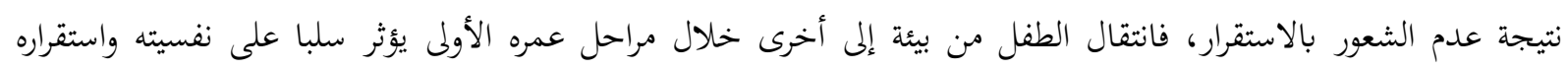

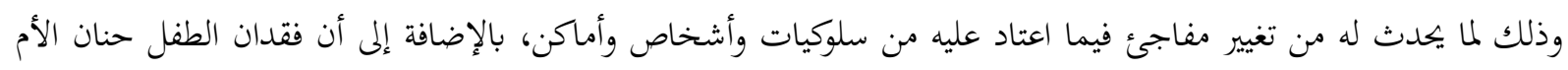
وعاطفتها وهو في عمر صغير سيكون منه في الغالب شخصية ضعيفة وغير مستقرة.

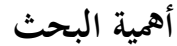

تتمثل أهمية البحث بضرورة مناقشة التعديل الأخير الذي طرحه البرلمان العراقي للمادة 57 من قانون الأحوال الشخصية

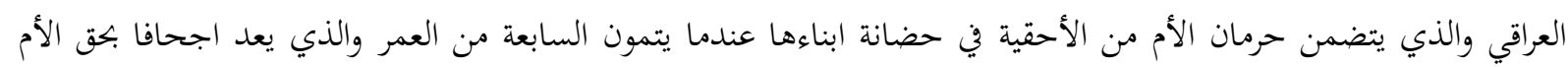

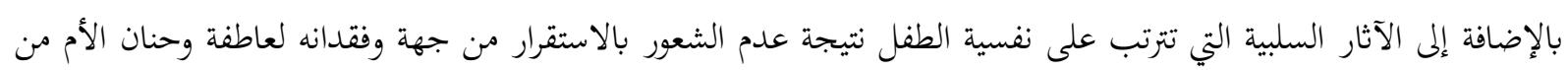

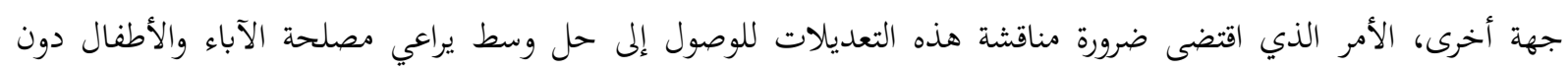
الإضرار بمصلحة الأمهات.

\section{هيكلية البحث}

سنقسم هذا البحث إلى مبحثين، نوضح في المبحث الأول ماهية الحضانة وأحكامها، والذي سنقسمه إلى مطلبين نوضح

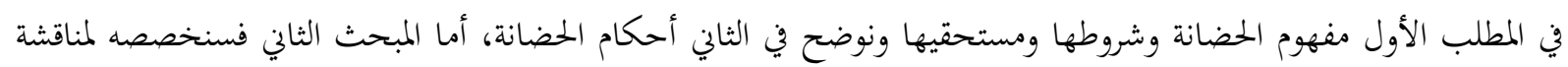
مقترح تعديل المادة 57 من قانون الأحوال الشخصية العراقي. 


\section{المبحث الأول}

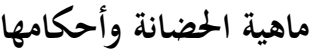

تعتبر الحضانة أثر من آثار الرابطة الزوجية وهي نوع من انواع الرعاية التي تقدم للطفل الصغير نتيجة عجزه عن القيام

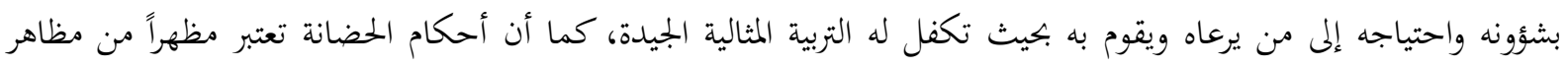
عناية الشريعة الإسلامية والقوانين الوضعية بالطفولة، وبغية توضيح المقصود بالحضانة وشروط استحقاقها ومستحقيها والإحاطة بهاه

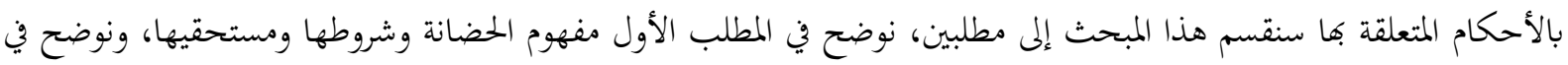
المطلب الثاني أحكامها.

$$
\text { المطلب الأول }
$$

\section{مفهوم الحضانة وشروطها ومستحقيها}

إن بيان مفهوم الحضانة يقتضي تعريفه لغةً واصطلاحاً، ومن ثم بيان أهم الشروط الواجب توافرها لاستحقاق الحضانة، ومن ثم بيان ترتيب مستحقي الحضانة، وعلى النحو الآتي: الفرع الأول: تعريف الحضانة

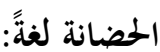

كلمة مأخوذة من الحضن وهي الضم إلى الجنب، يقال حضنت الصغير حضانته أي تحملت مؤنته وتربيته، والجمع احضان

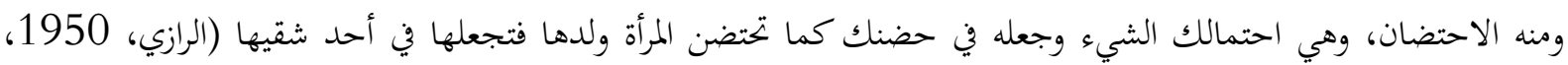
صفحة 142).

\section{الحضانة في الاصطلاح:}

عرف فقهاء الشريعة الإسلامية الحضانة بتعاريف متعددة حسب مذاهبهم، فعرفها الحنفية باهما "تربية الطفل ورعايته والقيام

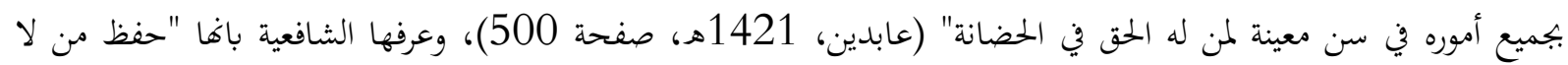

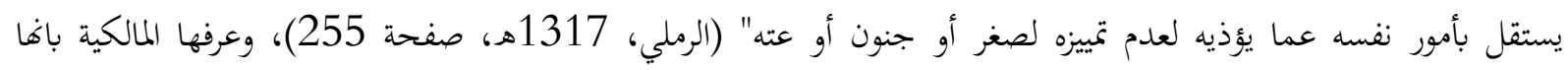

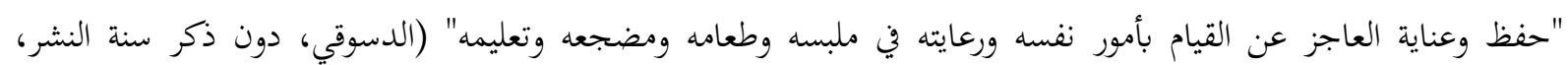

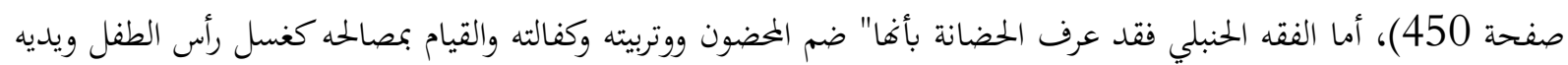
وثيابه والانفاق عليه وكل ما يتعلق بمصالحه" (البهوتي، دون ذكر سنة النشر، صفحة 495)، أما الفقهاء المعاصرين فقد عرفوا

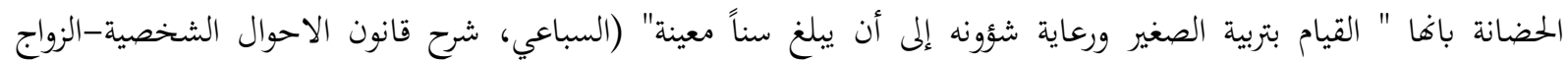

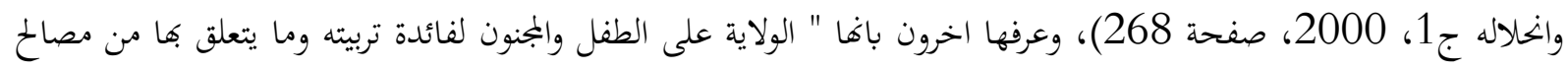

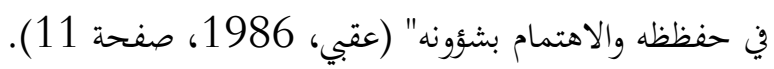
والملاحظ مما تقدم أن جميع التعاريف السابقة اختلفت في الفاظها إلا اغا تشاهت في معانيها، فجميعها تدور حول معنى واحد إلا وهو تربية المحضون ورعايته والقيام بشؤونه إلى أن يبلغ سناً معينة أما التشريع العراقي فلم يورد تعريفاً للحضانة في نصوص مواده القانونية مكتفياً بذكر أحكامه في قانون الأحوال الشخصية تاركاً المهمة للفقه على اعتبار أن وضع التعاريف هي مهمة فقهية. 


\section{الفرع الثاني: شروط استحقاق الحضانة}

لما كانت الغاية الأساسية من الحضانة هي تربية المخضون التربية المثالية الجيدة والعناية به وتنشأته النشأة الصحيحة، لذلك فقد احتاطت الشريعة الإسلامية وقانون الأحوال الشخصية العراقي في أمور الحضانة بأشتراطها شروطاً كثيرة يجب تونبه توافرها لاستحقاق الحضانة، فالقانون طابق الشريعة الإسلامية في بعض هذه الشروط وخالفها في البعض الآخر، وهي على النحو الآتي:

1

اتفق جميع فقهاء المذاهب الإسلامية على وجوب أن يكون الحاضن أو الحاضنة بالغا لان غير البالغ هو أحوج للحاضن

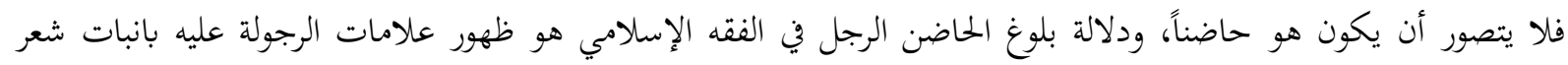

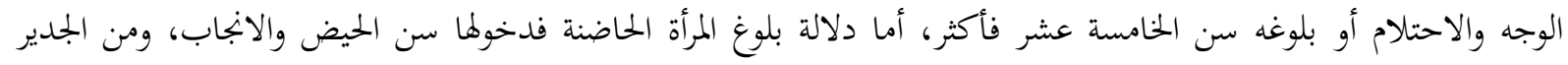

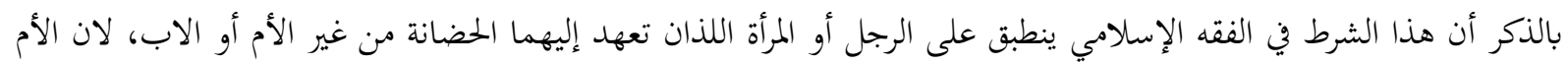

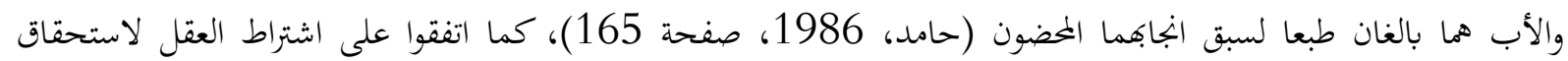

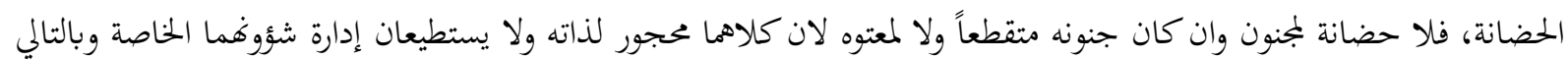
لا يصلحان لحضانة من هو بأمس الحاجة إلى الرعاية والاهتمام (نجيم، 1997، صفحة 179) (الشربيني، 2004، صفحة

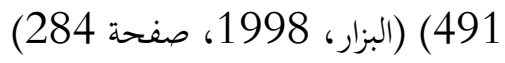

\section{3- 3- القدرة على الحضانة:}

لما كان المقصد الأساسي من الحضانة هو حفظ المخضون ورعايته والاهتمام به لذلك أتفق الفقهاء على اشتراط القدرة لإستحقاق الحضانة، أي لابد وأن يكون طالب الحضانة قادراً على رعاية المحضون وصيانته، فلا حضانة لكبير في السن ولا للعاجز ولا لمن لم الم

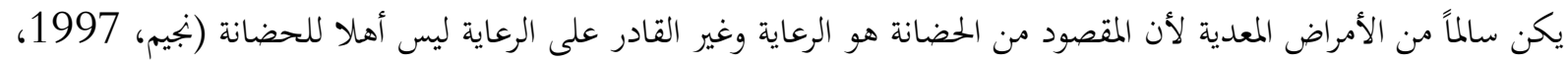

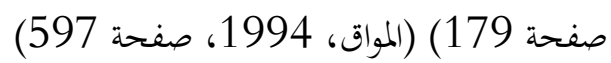

اختلف الفقهاء في تحديد معنى الأمانة، فذهب الحنفية إلى أن المقصود بالأمانة هو عدم الفسق أي أن لا يكون طالب

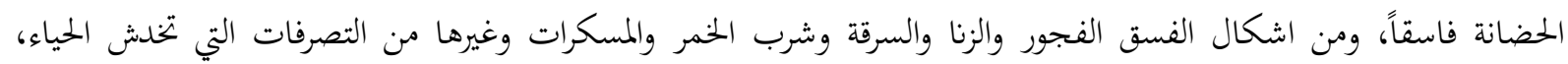

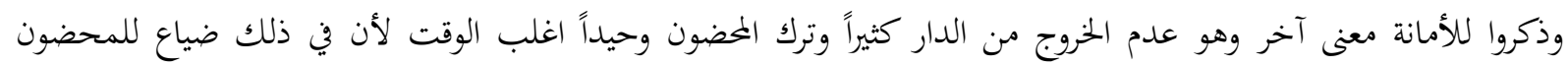

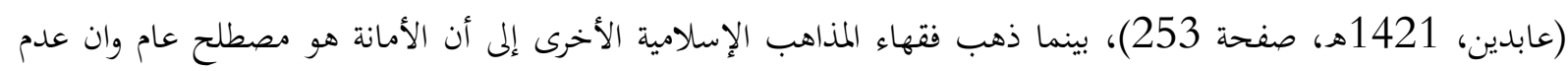

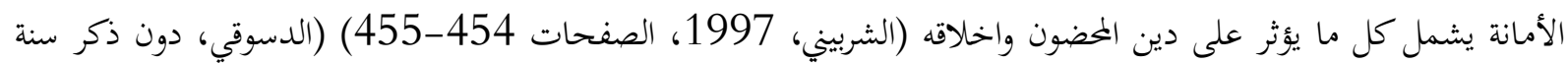
النشر، صفحة 528) (قدامة، 1997، صفحة 238).

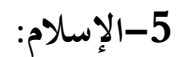

اختلف الفقهاء في هذا الشرط، فذهب الشافعية والحنابلة إلى اشتراط الإسلام لأستحقاق الحضانة أن كان المخضون

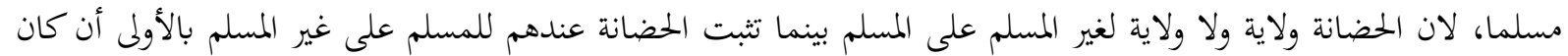
فيه مصلحة له (الشربيني، 1997، صفحة 455) (البهوتي، دون ذكر سنة النشر، صفحة 499)، بينما لم يشترط الحنفية والمالكية الإسلام لأستحقاق الحضانة ما لم يعقل المخضون الاديان أو يخاف عليه أن يألف غير الإسلام بأن تلقنه دينها أو تعلمه

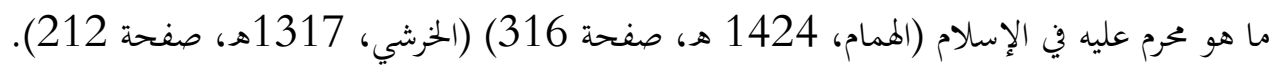




\section{6-عدم زواج الحاضنة بأجنبي:}

وهذا الشرط خاص بالنساء وسواء كانت الحاضنة أما أو غيرها، إذ اتفق فقهاء المذاهب الإسلامية الأربعة على اسقاط حق الحاضنة في الحضانة إذا تزوجت باجنبي عن المُضون، ذلك لان الغاية من الحضانة هي تحقيق مصلحة المخضون فإن تزوجت

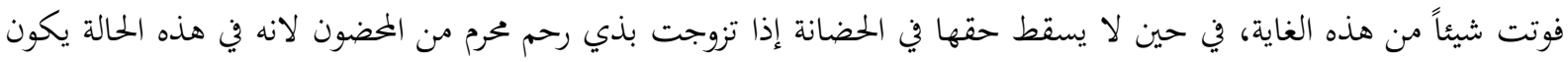

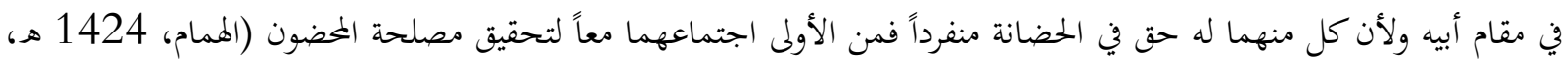
صفحة 316) (الشربيني، 1997، صفحة 456) (الدسوقي، دون ذكر سنة النشر، صفحة 529) (البهوتي، دون ذكر سنة

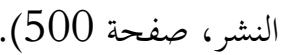

أما قانون الأحوال الشخصية العراقي فقد نص في المادة (57) الفقرة الثانية على " يشترط أن تكون الحاضنة بالغة عاقلة امينة قادرة على تربية المخضون وصيانته ولا تسقط حضانة الأم المطلقة بزواجها " والملاحظ أن شروط الحضانة المنصوص عليها في

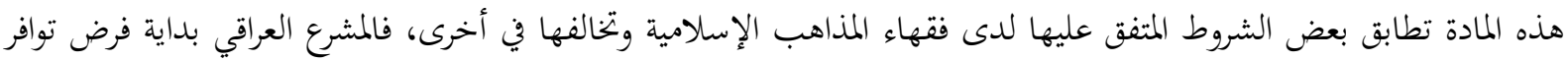
شروط الحضانة في الأم في حين لم يشترط في الأب أي شروط , فاشترط لكي تتولى الأم حضانة صغيرها البلوغ والعقل والقدرة

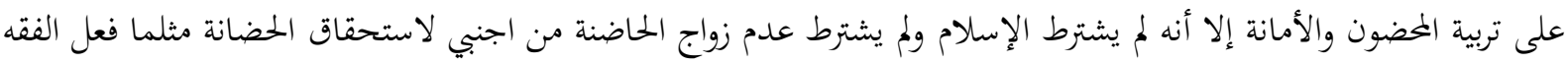

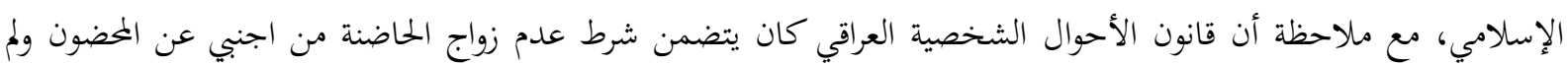

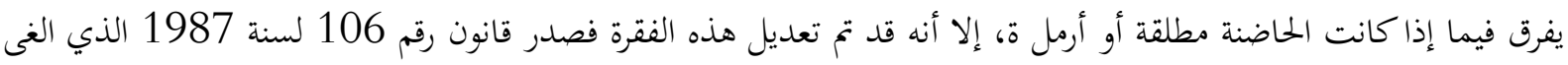

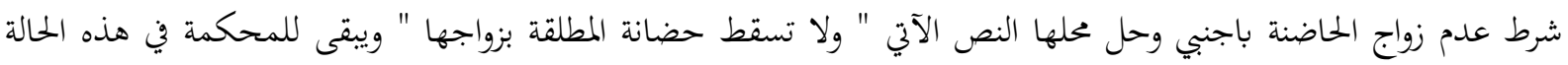

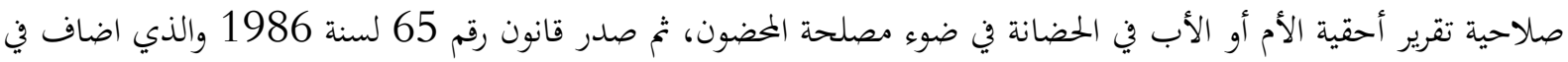

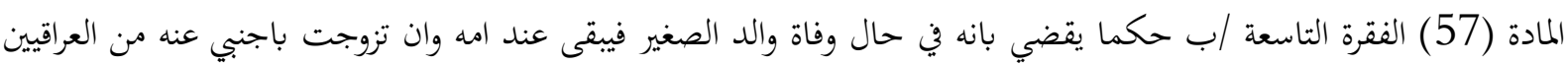
بشرط أن تكون الأم محتفظة ببقية شروط الحضانة وان تقتنع المحكمة بعدم تضرر الصغير من البقاء مع والدته وان يتعهد زوج الأم وأم

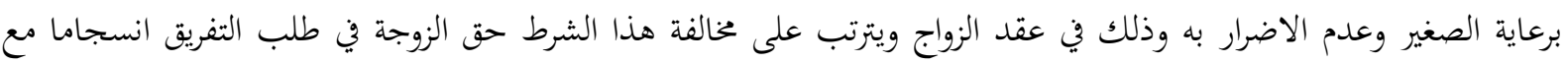

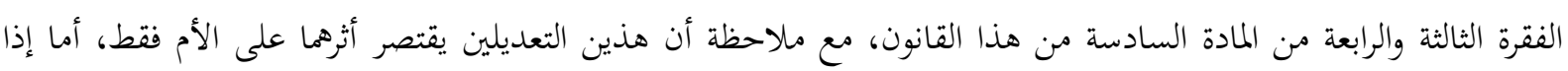
كانت الحاضنة غير الأم فلا تستفيد من هذه الأحكام

كما أنه وكما ذكرنا سابقا فإن المشرع العراقي في قانون الأحوال الشخصية قصر هذه الشروط على الحاضنة دون الحاضن

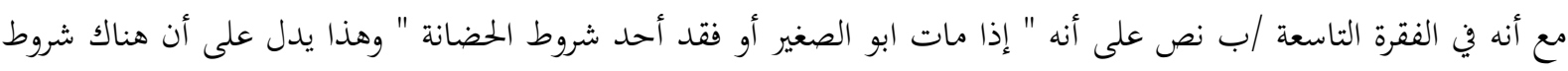
لابد من توافرها في الأب لاستحقاق الحضانة وهذه الشروط يوجب العقل أن تكون هي ذات الشروط المطلوب توافرها في

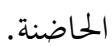

\section{الفرع الثالث: مستحقي الحضانة}

اتفق جميع فقهاء المذاهب الإسلامية على أن الأم هي احق الناس بحضانة الصغير إذا توفرت فيها شروط الحضانة كوغا

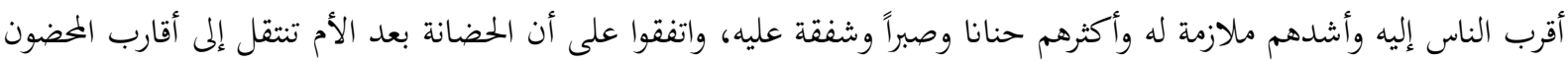

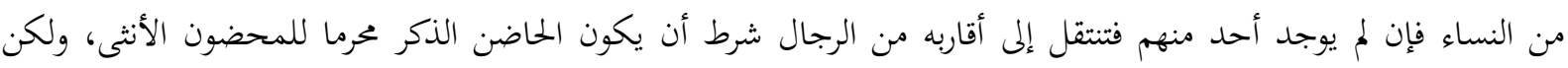
الخناف حدث بينهم في مراتب مستحقي الحضانة ولكل مذهب ترتيب تسلسلي مذكور في الكتب الفقهية ولا بجال لايراده هنا

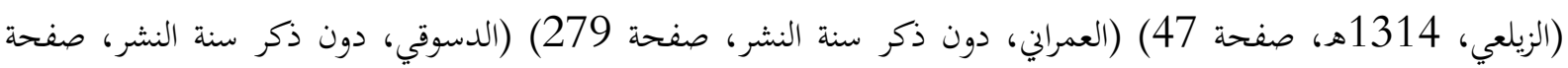

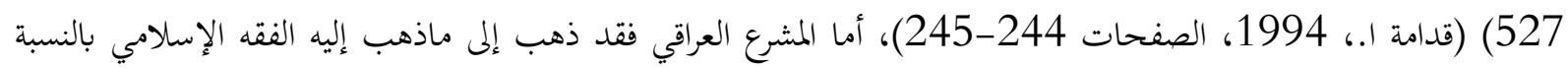

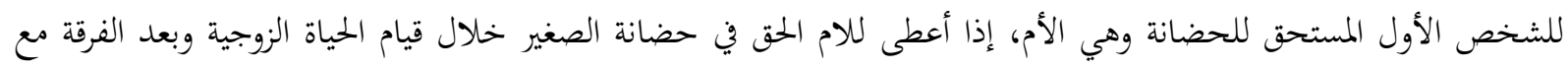


الاخذ بنظر الاعتبار مصلحة المضضون وذلك وفقا لما نصت عليه المادة (57) الفقرة الأولى والتي جاء فيها" الأم أحق بحضانة الولد

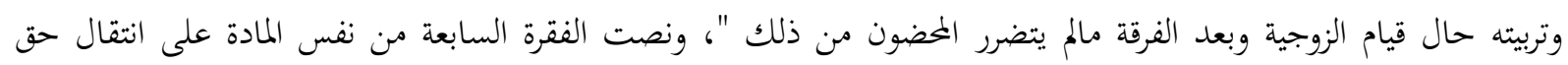

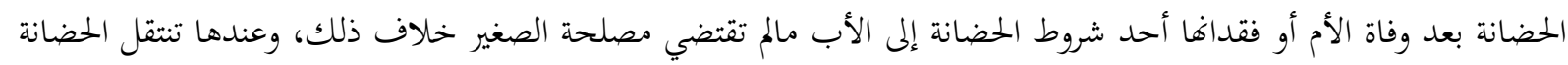
إلى شخص اخر يختاره القاضي مراعياً في ذلك كله مصلحة المحضون، ونصت الفقرة التاسعة على أنه في حال وفاة الأب أو فقدانه

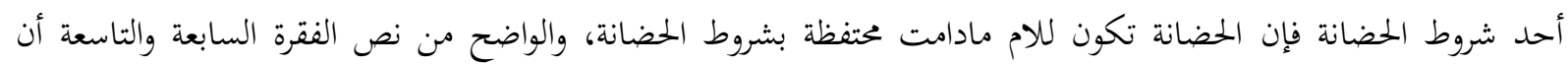

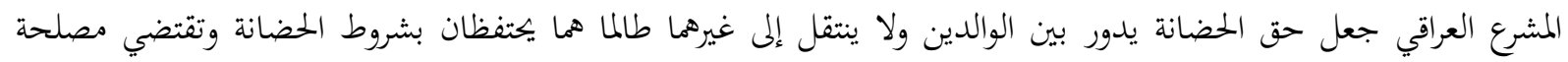

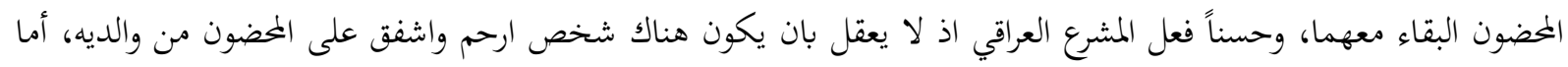

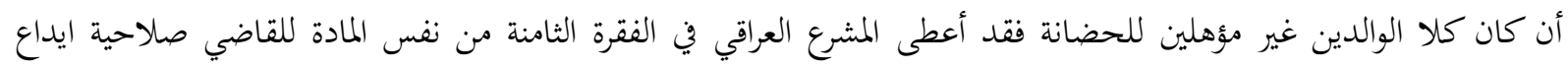

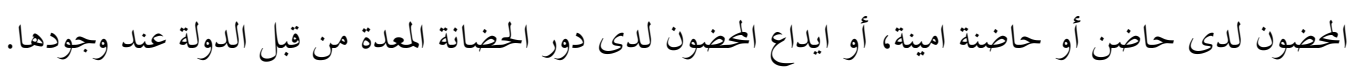
المطلب الثاني

أحكام الحضانة

بعد انحلال الرابطة الزوجية تنشأ عدة آثار تتعلق بحق الحضانة وهي تعتبر في نفس الوقت أحكاماً لها والتي نظمها الشرع بشكل مفصل بينما غفل القانون عن تنظيم بعضها، وهذه الأحكام هي مدة الحضانة ومشاهدة المُضون والسفر بالمضون، وهنو ما سنبحثه في هذا المطلب وعلى النحو الآتي:

الفرع الأول: مدة الحضانة

اتفق الفقهاء على أن مدة حضانة الصغير تقدر بقدر حاجة المحضون إليها، أي تبدأ منذ ولادته وتنتهي بانتهاء حاجة

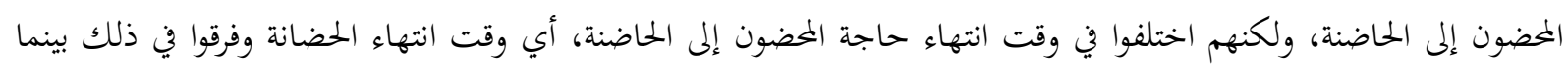
إذا كان المضضون ذكراً أو أنثى، فذهب الحنفية إلى أن حضانة الذكر تنتهي عند السبع سنوات والأنثى عند التسع سنوات (عابدين، 1421هـ، صفحة 255)، وذهب الشافعية إلى أن الحضانة تبقى للام إلى أن يبلغ الصبي والفتاة سن التمييز والادراك

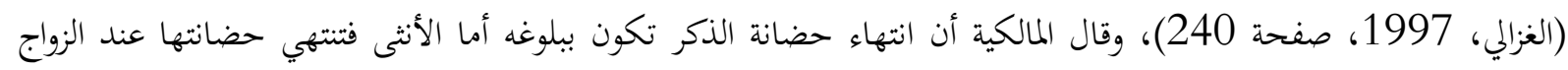

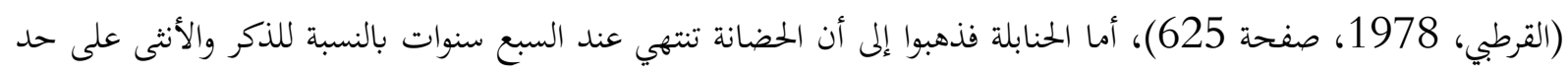

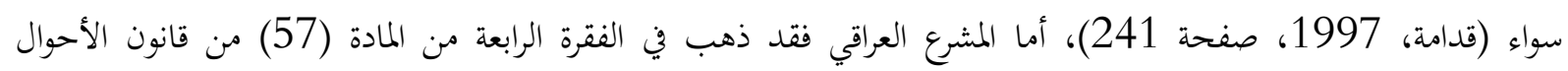
الشخصية العراقي إلى أن مدة حضانة الصغير تنتهي عند اتمام العاشرة من العمر، مع امكانية تمديدها إلى حين اكماله الخامسة

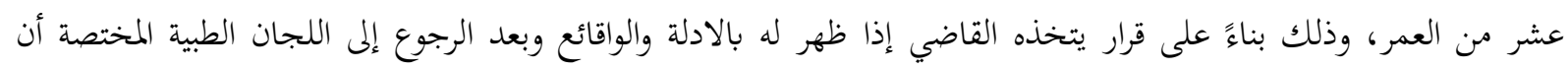

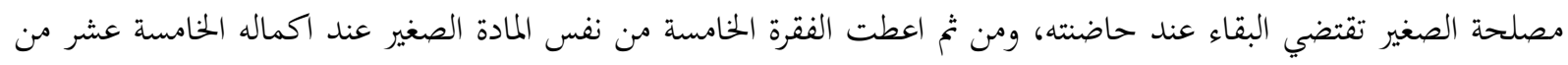

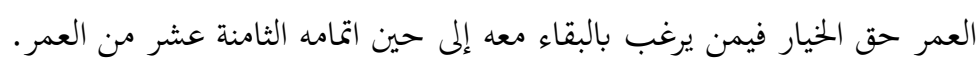

الفرع الثاني: مشاهدة المخضون

لما كانت الغاية الأساسية من الحضانة هي حفظ المخضون وتربيته ورعايته، لذلك وجب على الطرفين التعاون بينهما لتحقيق تلك الغاية، اذ أن مسؤولية المخضون تقع على عاتق كلا الطرفين في ظل قيام الحياة الزوجية وحتى بعد الانفصال، فالطفل

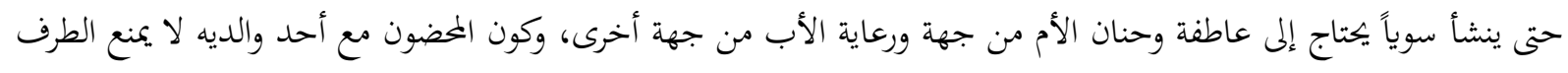

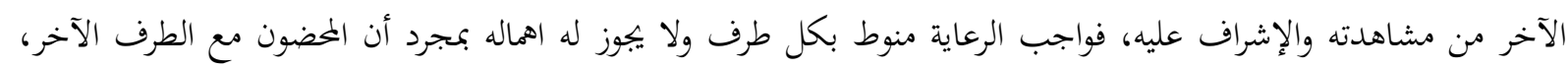

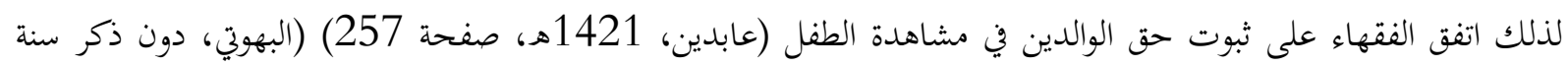

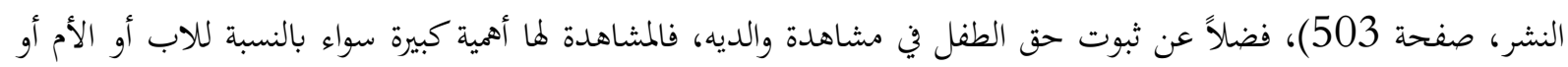


المخضون، فبالنسبة للاب والأم المشاهدة تحقق غايتان اولما اشباع عاطفة الابوة والأمومة، والأخرى لمتابعة شؤون الطفل وتربيته والاطمئنان عليه، أما بالنسبة للمحضون فمشاهدة والديه حق له كما اهما من باب صلة الارحام التي امرنا الله تعالى هما.

اما المشرع العراقي فلم ينظم أحكام المشاهدة بشكل واضح ودقيق، بل اقتصر فقط على اعطاء الأب حق النظر في شؤون

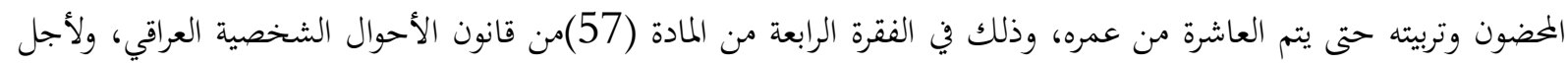

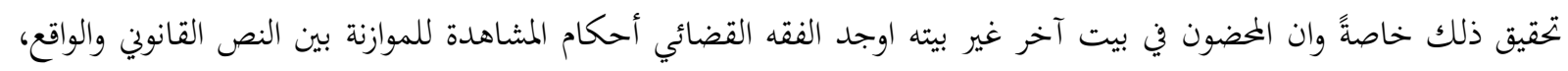

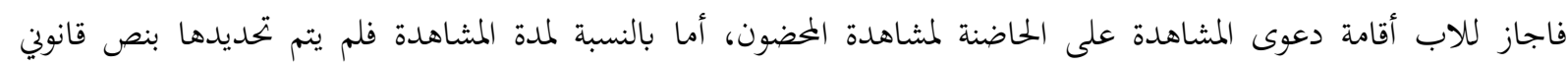

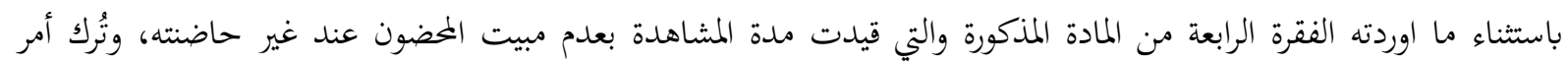

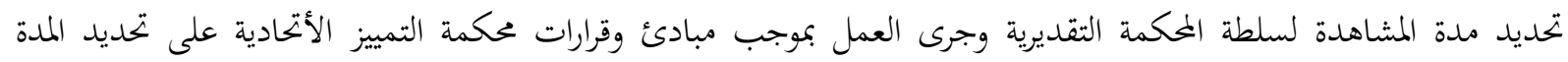

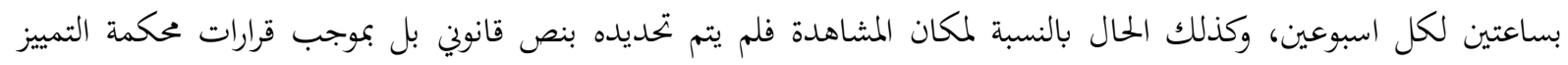

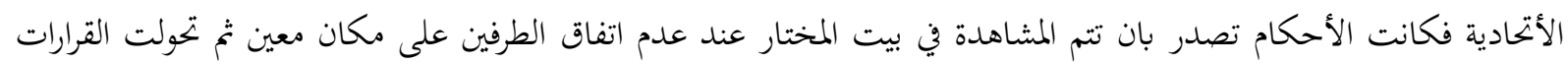

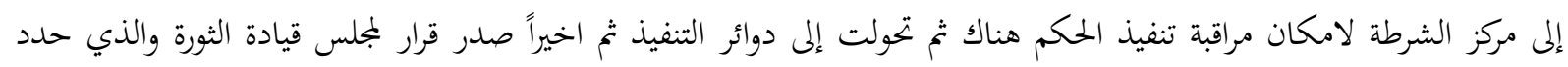

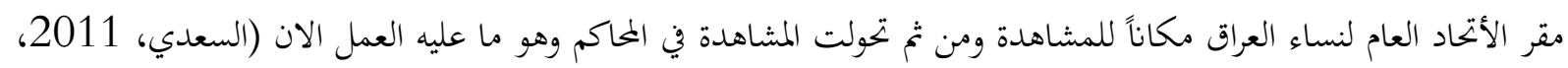

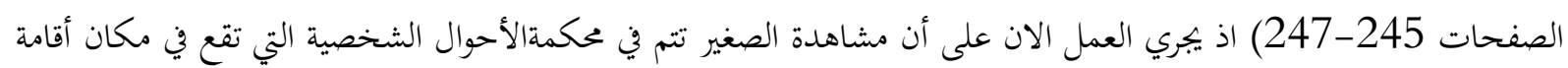
الصغير مساء كل يوم جمعة.

\section{الفرع الثالث: السفر بالخضون}

اختلف الفقهاء في حكم السفر بالمخضون وذلك بحسب الأساس الذي أقاموا عليه الحكم، فالحنفية قسموا السفر إلى قريب

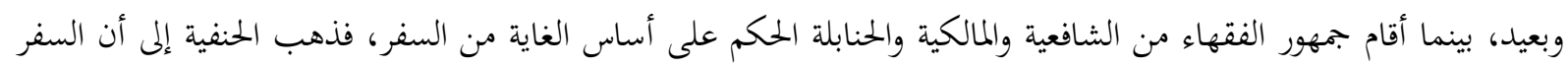

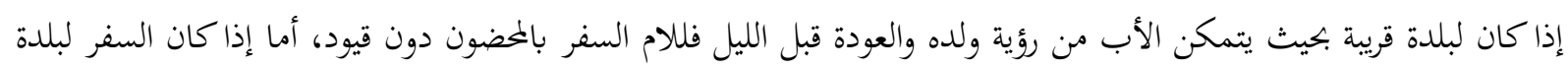

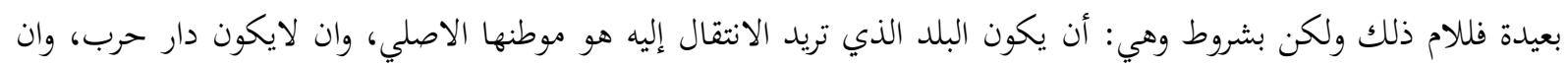

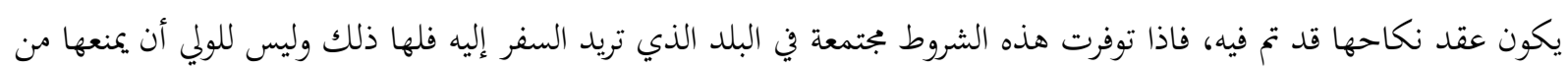

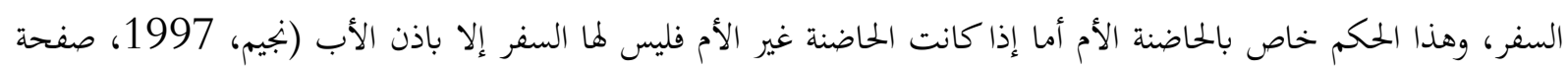

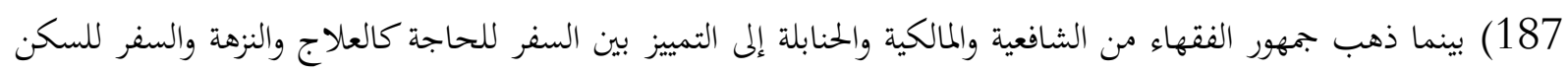

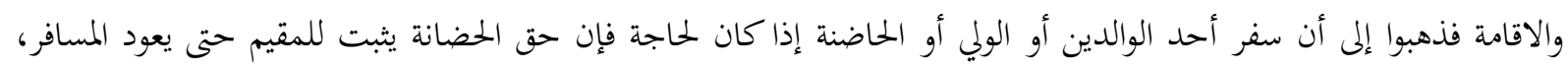

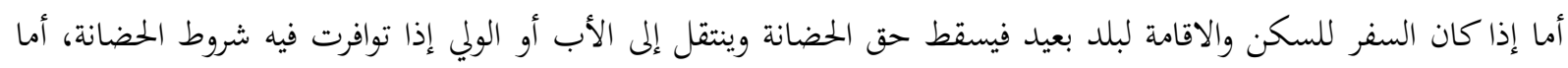

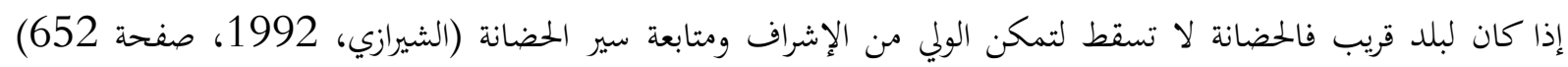
(الدسوقي، دون ذكر سنة النشر، صفحة 531) (قدامة، 1997، صفحة صنحة 217)|مان قانون الأحوال الشخصية العراقي فلم

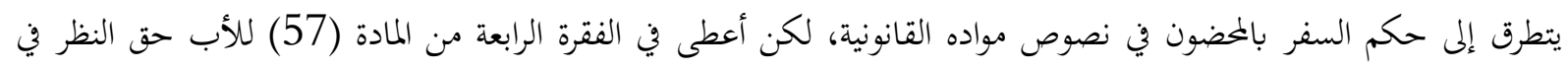

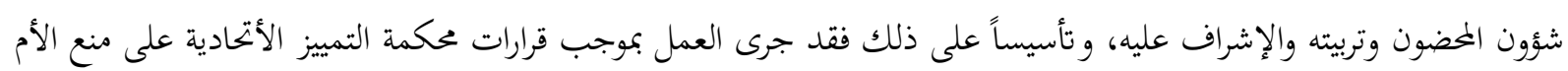

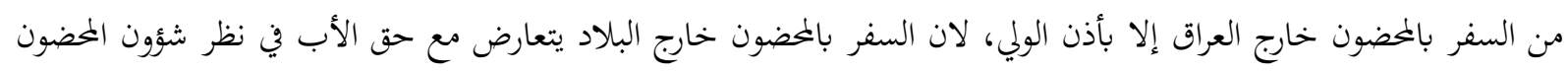




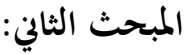

\section{مناقشة مقترح تعديل المادة 57 من قانون الأحوال الشخصية العراقي}

الحياة الزوجية رابطة مقدسة يتمخض عنها آثار مادية ومعنوية لا تقتصر على السلوك الاعتيادي لحياة الزوجين (الرجل، المرأة)

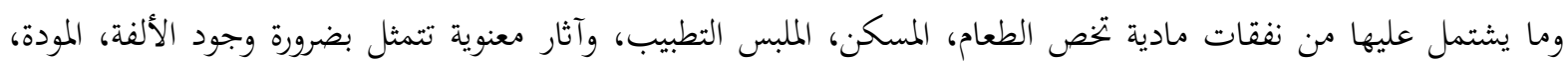

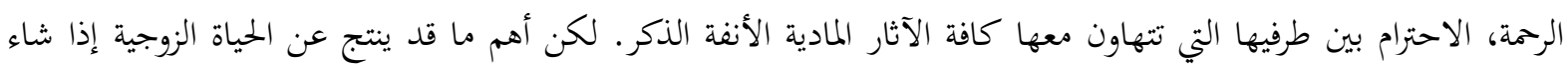

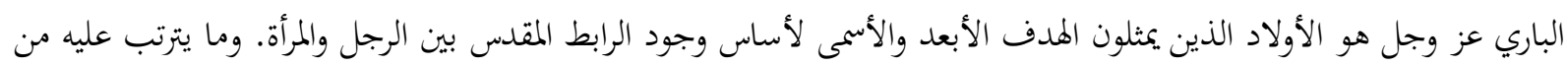
ضرورة رعاية مصالحهم.

فقد قسم الله سبحانه وتعالى واجبات الوالدين في حفظ الأولاد على مراحل حياتم فخص الأم بالحمل والولادة والرضاعة

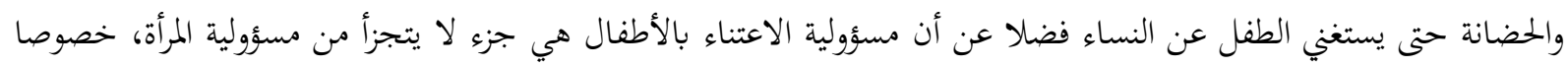

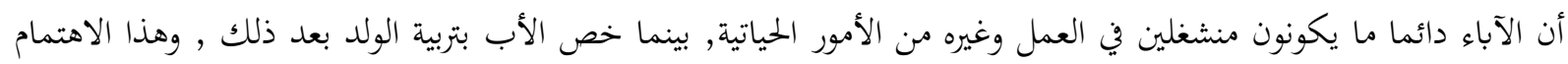

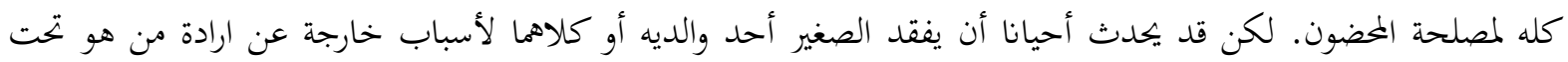

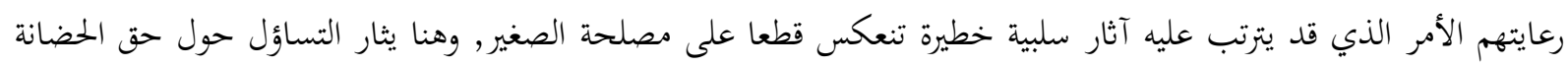

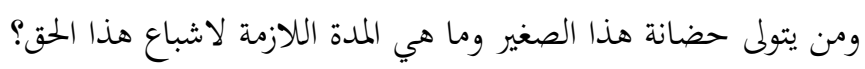
إن قانون الأحوال الشخصية العراقي رقم 188 لسنة 1959 قد نظم حق الحضانة بتسع فقرات تضمنتها المادة 57 منه

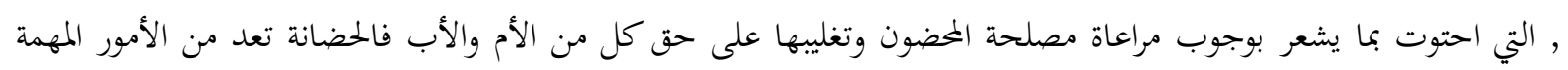

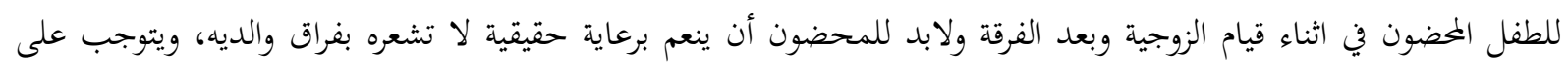

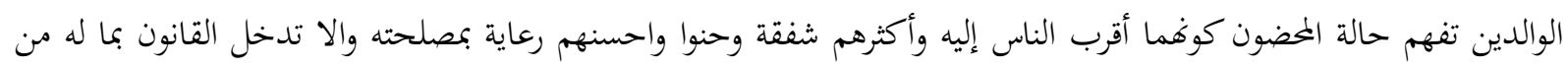

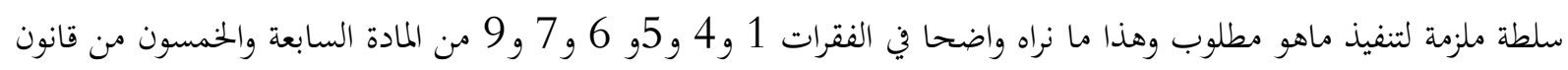
الأحوال الشخصية.

إلا أن البرلمان العراقي أجرى قراءة أولى في بداية شهر تموز الجاري لمشروع تعديل قانون الأحوال الشخصية رقم 188 لعام

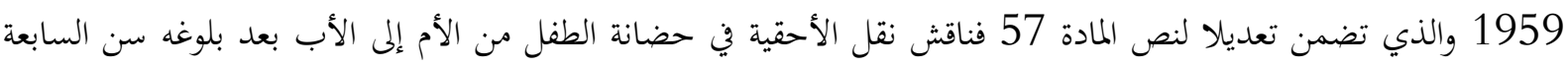

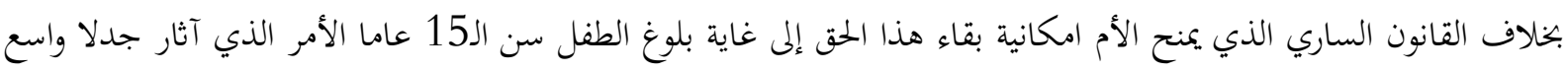

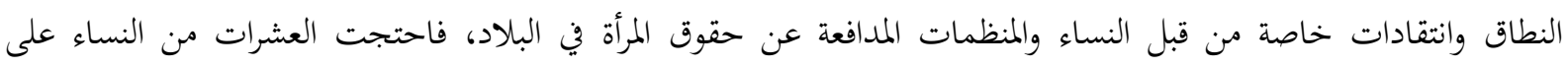
التعديلات المقترحة كوها تنص على أن تكون

الأم المطلقة أحق بحضانة الولد حتى يتم السابعة ويشترط عدم زواجها لأخذ الحضانة وبذلك، فإن الأصل يصبح حرمان

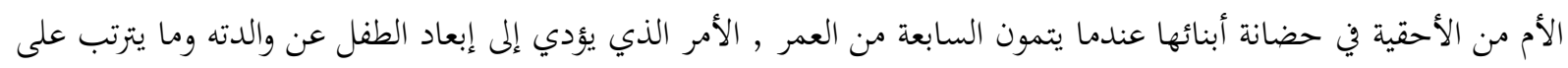
هذا من تبعات نفسية كبيرة خاصة وان عمر السابعة يعد من الاعمار الحرجة التي يجب أن يستمتع فيها الصغير بالاستقرار كوها

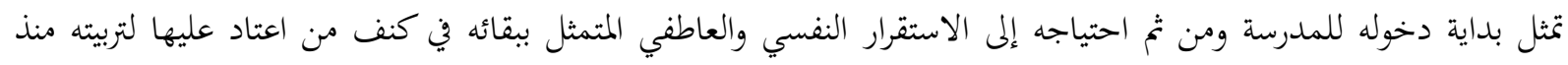

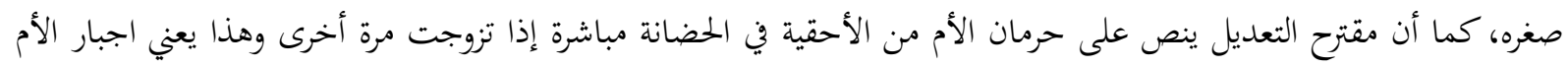

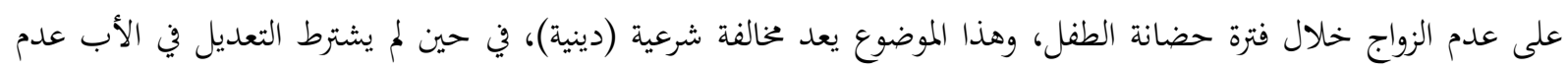

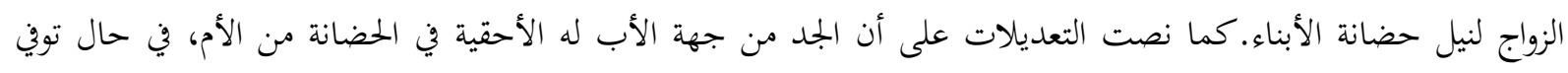
الأب أو انتفت لديه شروط الحضانة هذا من جهة، ومن جهة أخرى تدعم مطالب تعديل القانون آراء قانونية ودينية ترى في 
النص القانوين الحالي إجحافا في حق الآباء، وإضرارا بمصلحة الأطفال أيضا، مما يتطلب ضرورة البحث عن حل وسط يراعي مصلحة الآباء والأطفال دون الإضرار بمصلحة الأمهات.

وبغية تسليط الضوء على مقترح التعديل اعلاه لابد لنا من مناقشة الفقرات التي نص عليها التعديل والفقرات التي اغفل النص عليها وكالاتي:

1- أن مقترح التعديل بارجاعه سن الحضانة إلى سن التمييز الذي حدده المشرع العراقي بسبع سنوات كاملة بمقتضى نص الفقرة الثانية من المادة (97) من القانون المدني العراقي في الوقت الذي كان النص الموجود في قانون الأحوال الشخصية يجعل الثعل حضانة

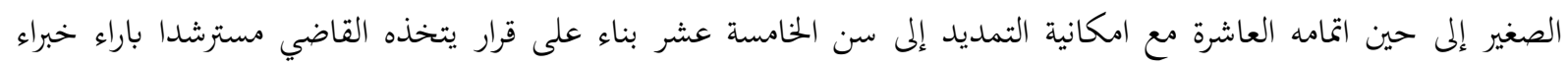

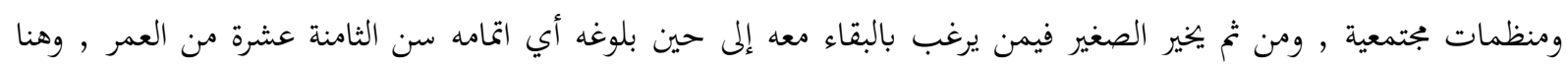

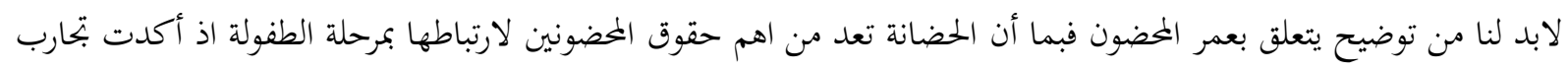

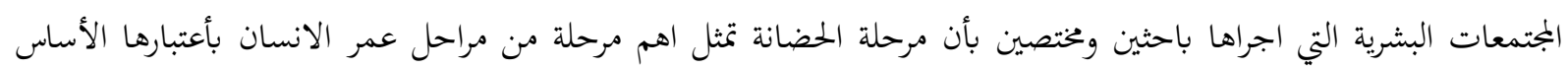

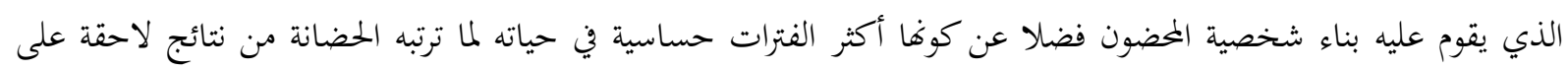

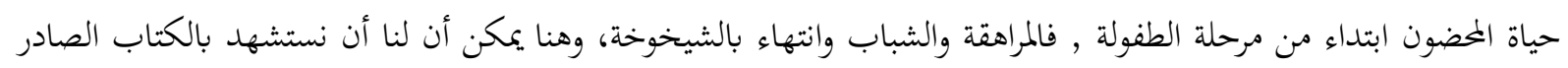

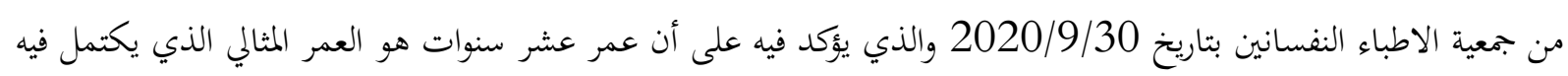

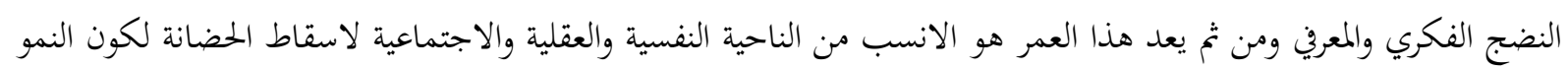
النفسي يفرق بين عمر 10 سنوات كمرحلتين منفصلتين من الناحية النفسية , ونظرا لان الاطراف المؤيدة لتعديل المادة (57)

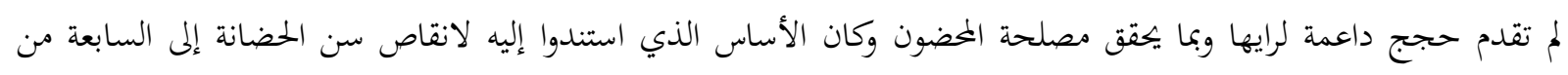

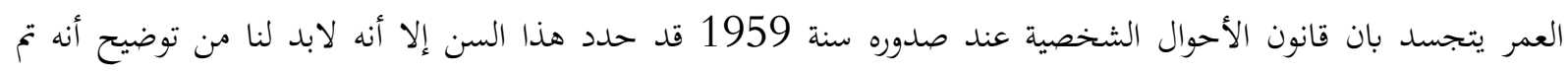

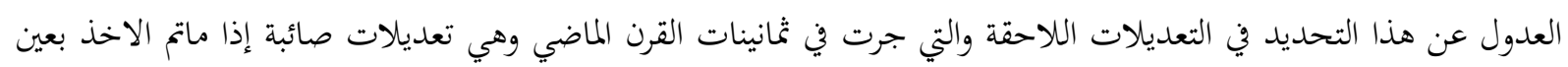
الاعتبار الاراء الطبية والنفسية والاجتماعية وهو ايضا ما يتم العمل به في الدول العربية ذات التراث الإسلامي والقانوين العريق. 2- أما فيما يتعلق بما نص عليه مشروع التعديل بنقل الحضانة من الأم إلى الأب بمجرد بلوغ الصغير سن السابعة فهو يتنافف

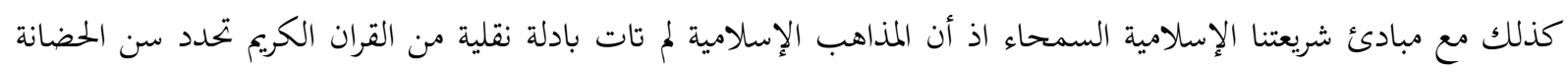

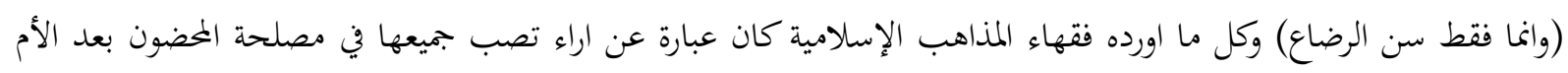

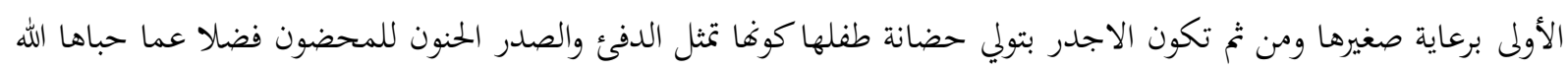

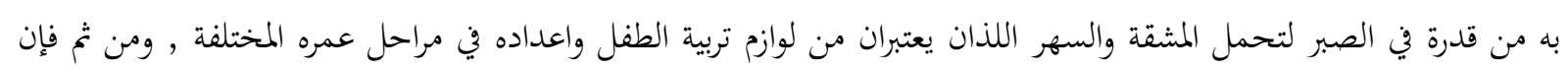

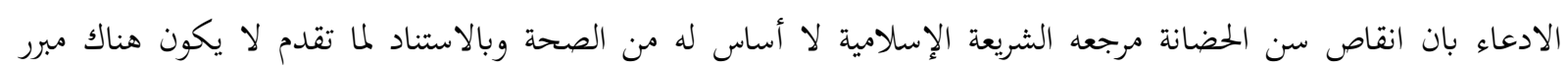
لانقاص سن الحضانة إلى السابعة.

3- وفيما يتعلق بسحب الحضانة من الأم بمجرد زواجها وحتى لو لم يبلغ الصغير السابعة من العمر فلابد من التنويه بداية إلى أن

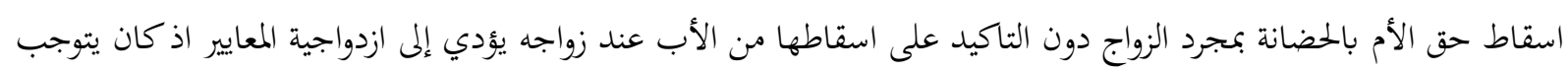

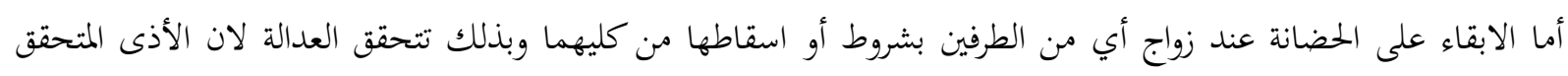

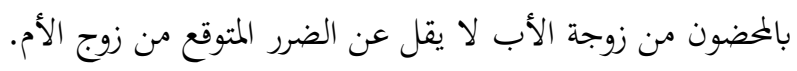

كما أن هذا الاسقاط يخالف توجهات الشريعة الإسلامية لانه سيجبر الأم على عدم الزواج خشية فقدان صغيرها

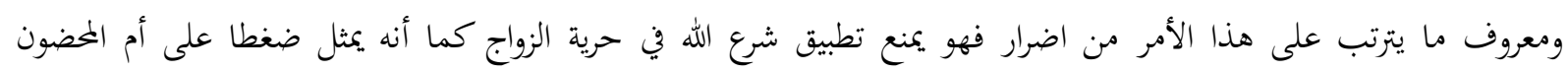
لاضطرارها إلى البقاء وحيدة دون زواج. 
4- أما فيما يتعلق بالفقرة الواردة بمقترح التعديل والتي تنص على انتقال الحضانة من الأب إلى الجد الصحيح (اب الأب وان علا)

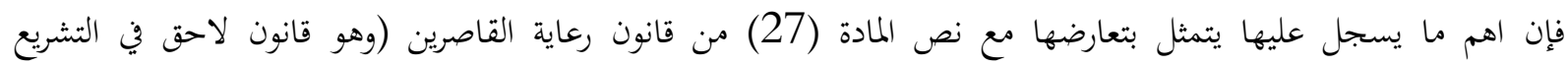

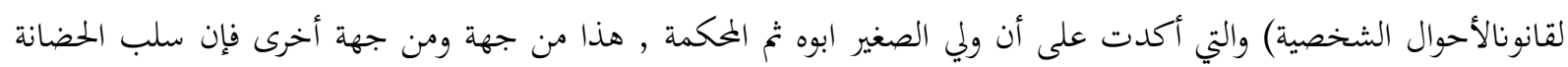

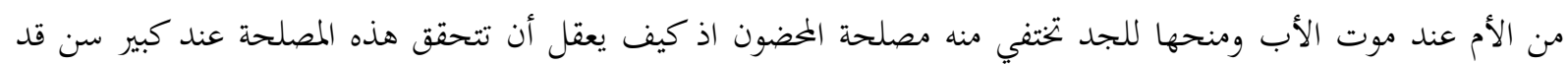
لايقوى على رعاية نفسه ناهيك عن مصلحة طفل.

كما أن هذه الفقرة تتعارض مع حقوق الارامل وخاصة زوجات الشهداء فاين المصلحة من سلب الحضانة منهن إذا بلغ المخضون السابعة وهو أصلا بدون أب سواء تزوجت هذه الارملة أم لا. 5- لابد من التاكيد على أن التعديل اغفل ما يضمن مصلحة المحضون اذ كان لابد أن يشتمل على حكم بمبيت المحضون مع والده لان نص الفقرة الرابعة من المادة 57 السابق يمنع ذلك، فكان يتوجب تنظيم هذان انلان الأمر خاصة وانه ينسجم وأحكام المادة 9 من اتفاقية حقوق الطفل الصادرة عن الجمعية العامة للأمم المتحدة في 20 تشرين الثانيمن 1989 والمصادق عليها من قبل العراق بموجب القانون رقم 3 لسنة1994 ، حيث ورد في نص الفقرة (1) من المادة أعلاه الآتي (تضمن الدول الأطراف عدم فصل

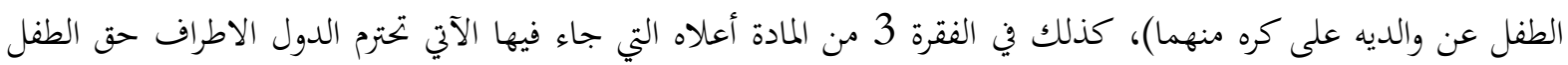

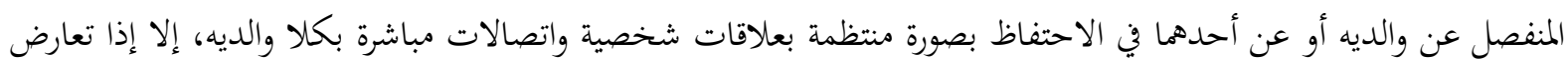
ذلك مع مصالح الطفل الفضلى.

6- إذا كان قانون الأحوال الشخصية النافذ قد رجح حق الحضانة للأم كجزء من واجب الرعاية والحماية والصيانة المقرر عليها

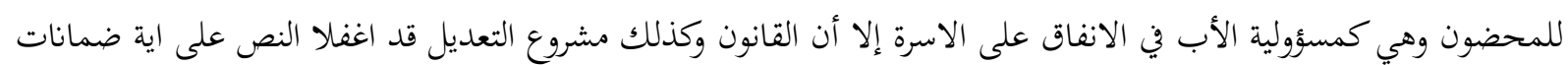

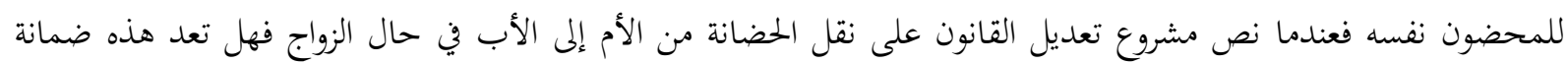

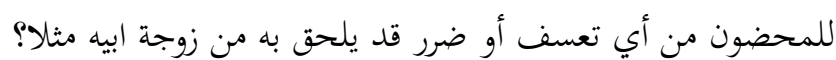
إن الإجابة على السؤال اعلاه تقتضي التاكيد على أنه لا يكفي وجود المخضون مع الأم أو الأب بدون ضمانات أساسية

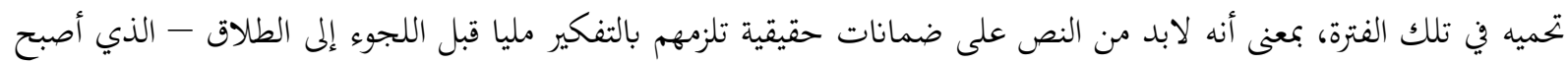

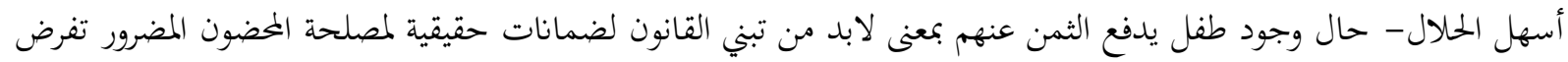

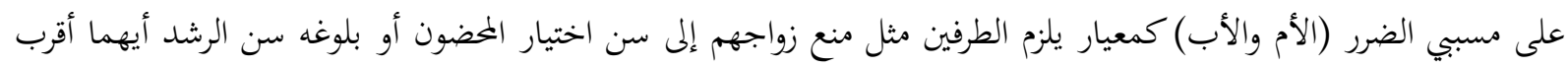

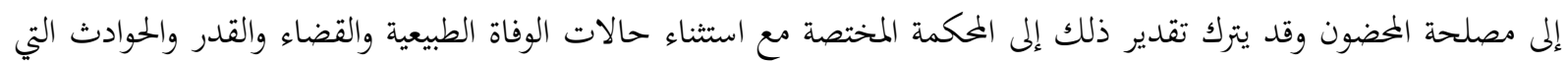
لا دخل لأرادة الشخص بها، أو النص على ضمانة مالية تستقطع من الأب مقدما لمصحلة المخضون وتودع لدى دائرة رعاية

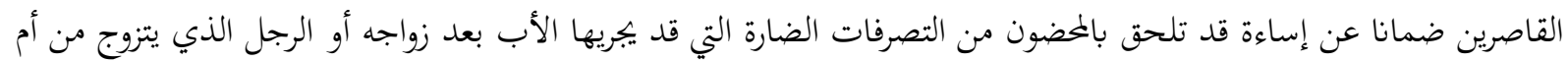

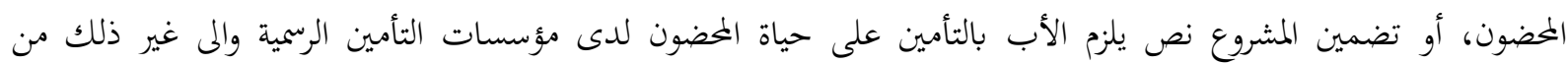

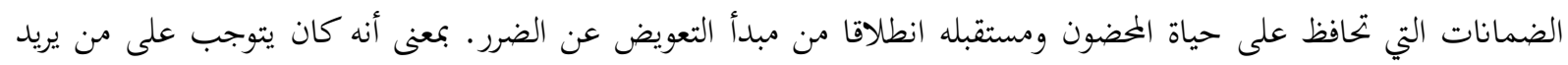

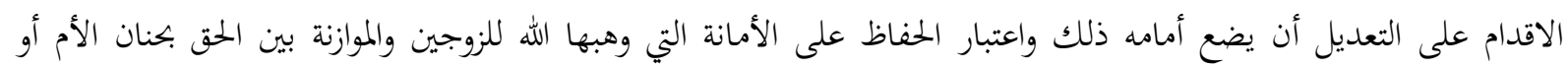

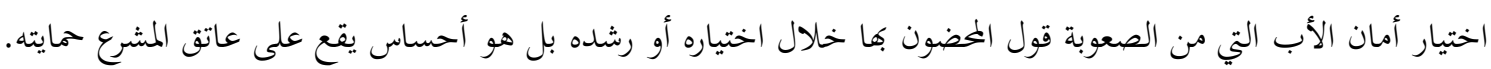
7- أن قانون الأحوال الشخصية العراقي قد ترك تحديد مكان مشاهدة المحضون لاتفاق الطرفين فإن لم يتفقا فقد كانت المشاهدة

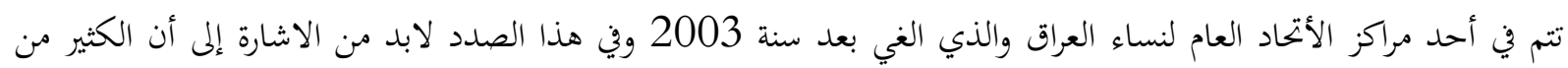

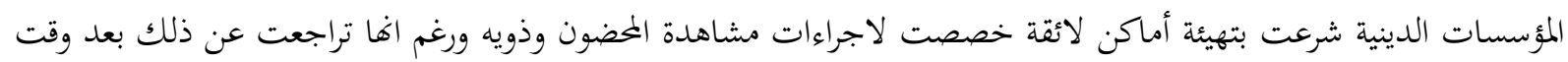
قصير بسبب ما تم رصده من خلافات وتصرفات تكون بالضد من مصلحة الصغير وطالبت الدولة بتحمل مسؤوليتها من خلال 
توفير أماكن تتوفر فيها ضمانات حقيقية تحقق المشاهدة بجو مريح لذلك كان الأولى بمشروع التعديل تنظيم مكان وزمان مشاهدة المخضون لاهمية هذا الأمر.

8- كما أنه في بعض الحالات - وهي من الأمور التي تم رصدها - قد لا يحضر الأب إلى موعد المشاهدة وما يترتب على ذلك فيك

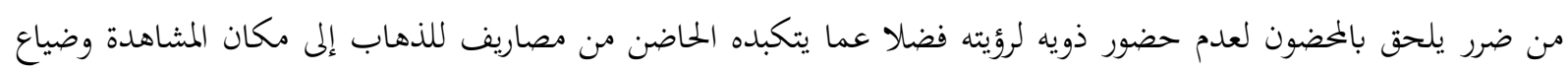

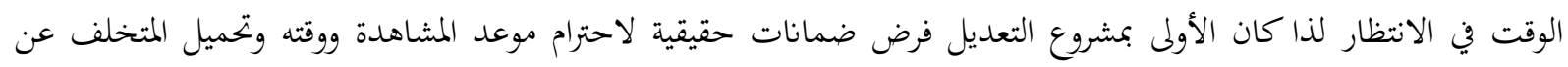
الحضور دون عذر مشروع غرامات فضلا عن عقوبات قد تصل إلى درجة حرمانه من المشاهدة لان عدم حضوره لمشاهدة صغيره

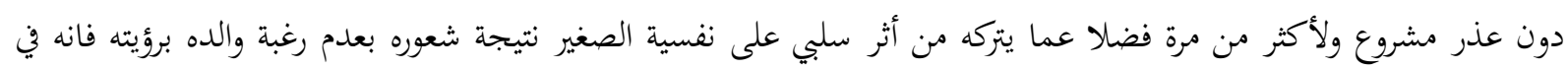
نفس الوقت دليل على عدم رغبة ذلك الأب بمتابعة شؤون صغيره.

9- أن موقف المشرع العراقي في قانون الأحوال الشخصية من مسألة الشروط المشتركة للحاضنين التي تتعلق بالحاضن لاستحقاقه

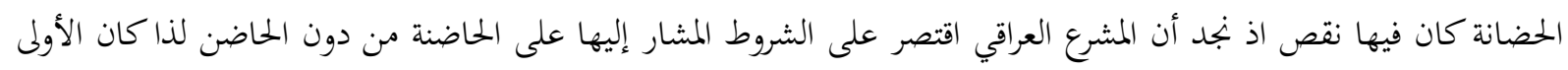

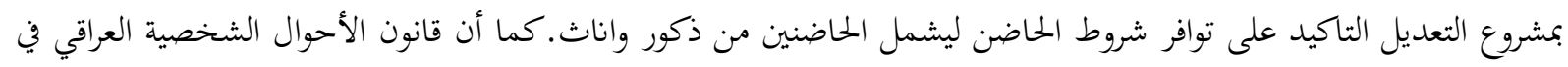

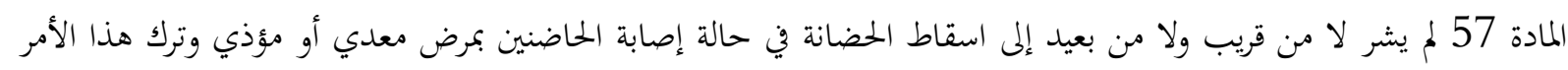
إلى مبادئ الشريعة الإسلامية الأكثر ملائمة لنصوص هذا القانون في حين كان الأولى بلى به النص على ذلى ذلك حفاظا على مصلحة المخضونن وهو أمر لم يتطرق إليه مشروع التعديل. 10- واخيرا فقد جاء قانون الأحوال الشخصية العراقي خاليا من أي نص تلميحا أو تعريفا لمسألة السفر بالمضون من قبل امه

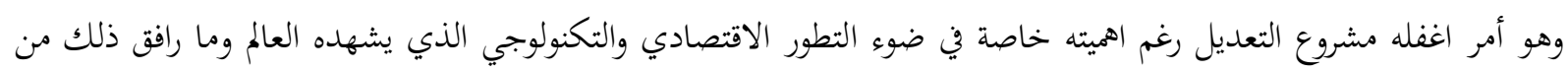

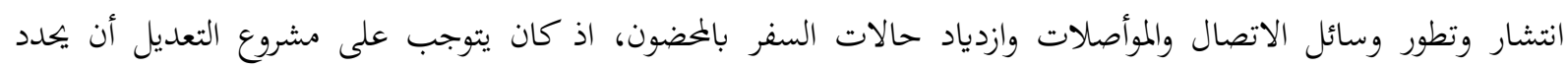

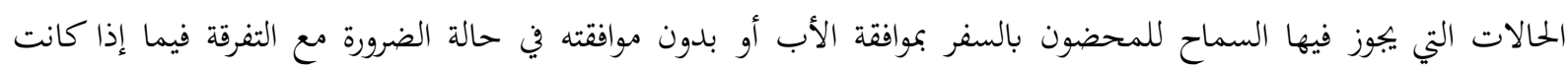
الحاضنة عراقية أم أجنبية، والتاكيد على حق الأب في حالة تخوفه من سفر المخضون في طلب كفيل.

الخايتمة

بعد الانتهاء من هذا البحث توصلنا إلى جملة من النتائج والتوصيات وعلى النحو الآتي: أولاً- النتائج

1-نظم المشرع العراقي موضوع الحضانة في المادة 57 من قانون الأحوال الشخصية العراقي رقم 188 لسنة 1959 إلا أنه لم

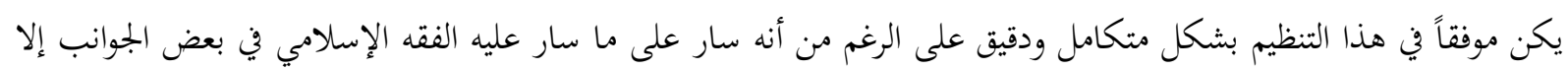
أنه لم يخلو من النقص التشريعي بالإضافة إلى عدم الدقة في تنظيم بعض الجوانب الأخرى. 2-نص المشرع العراقي على أربعة شروط يجب توافرها في الحاضنة لاستحقاق الحضانة وكان الاصح على المشرع العراقي ذكر مصطلح الحاضن ليشمل الذكر والأنثى. 3-نص المشرع العراقي على أن مدة حضانة الصغير تنتهي عند اتمام العاشرة من العمر، مع امكانية تمديدها إلى حين اكماله

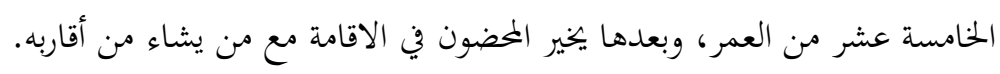

4-لم يتطرق المشرع العراقي إلى الأحكام الخاصة بمشاهدة المحضون من حيث مدة المشاهدة ومكاها وكذلك لم يتطرق المشرع

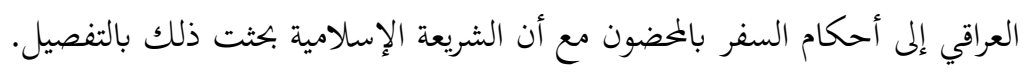


5-نظم المشرع العراقي الإشراف على الخضون ومدة الحضانة وتمديدها في فقرة واحد من المادة 57 بشكل متداخل وغير واضح،

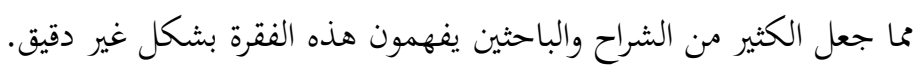

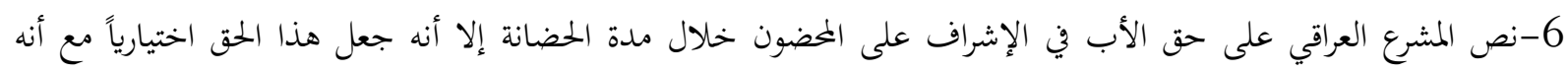

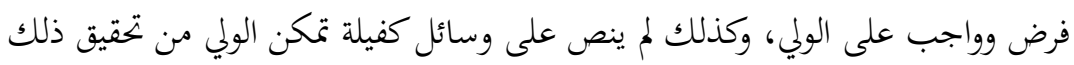

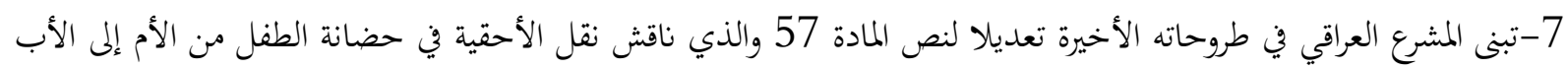

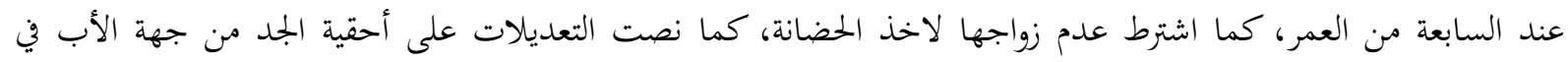

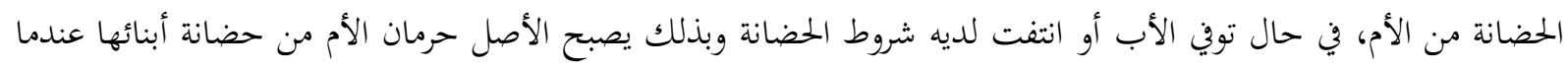

$$
\text { ثيتمون السابعة من العمر . ثلاًاً التوصيات }
$$

1- رفض مقترح التعديل المقدم إلى مجلس النواب (والمتعلق بانقاص سن الحضانة إلى سبع سنوات واسقاطها عن الأم في حالة

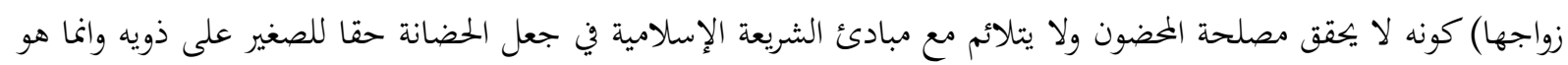

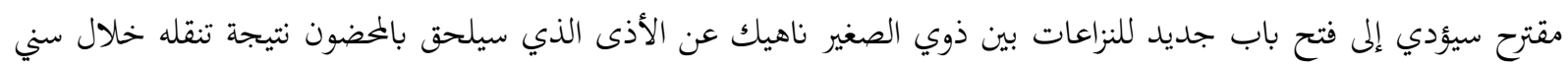

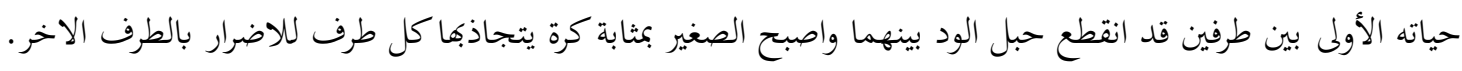

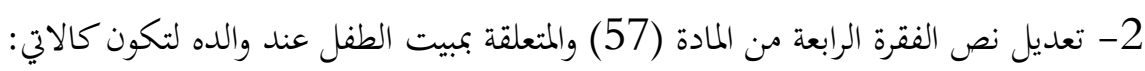
- للاب النظر في شؤون المخضون وتربيته وتعليمه حتى يتم العاشرة من عمره.

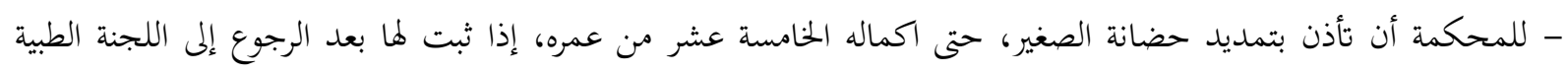
المختصة أن مصلحة الصغير تقضي ذلك.

- للمحكمة بناء على طلب من الأب أن تأذن بمبيت المضضون عنده لمدة تحددها إذا اقتضت مصلحة المخضون ذلك.

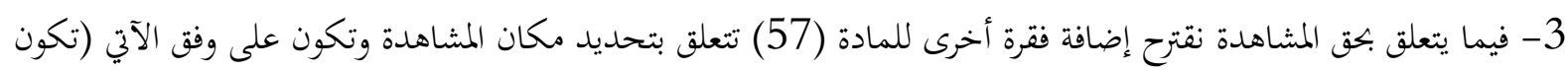

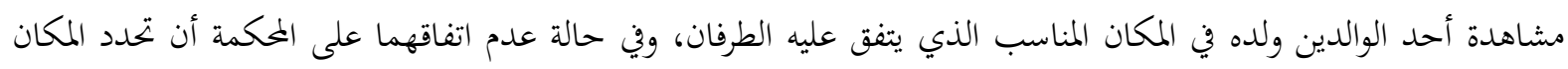
المناسب للمشاهدة في المكان الذي تقيم فيه الأم )

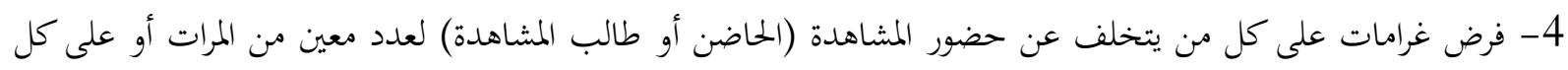

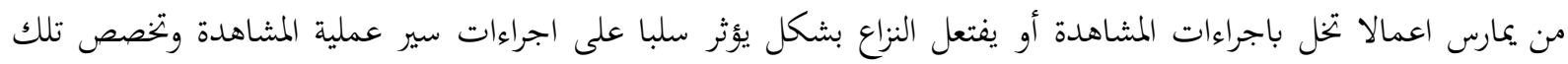
المبالغ في انشاء وتطوير أماكن خخصصة للمشاهدة تحت انظار السلطة وبحمايتها.

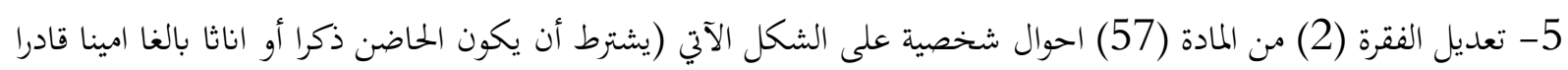

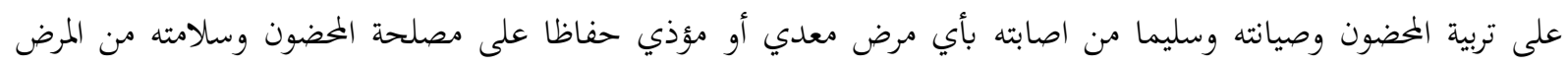

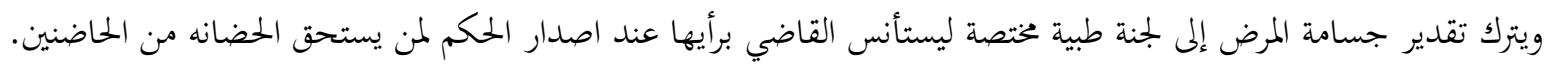

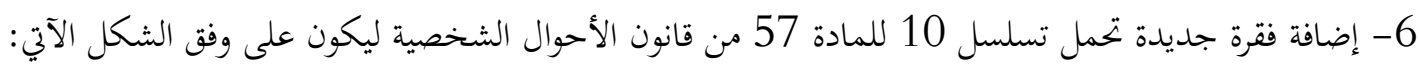

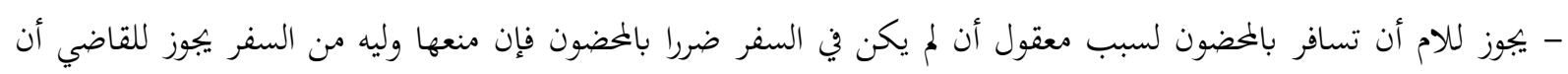

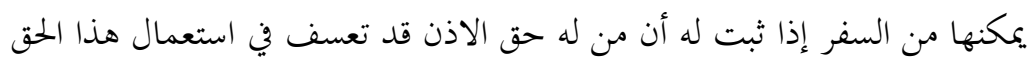

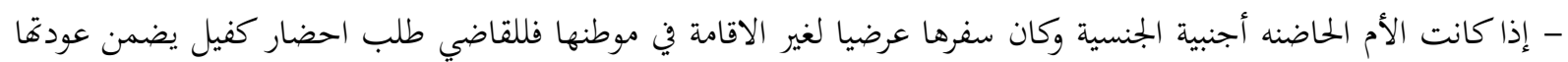

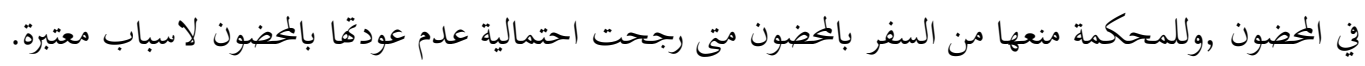




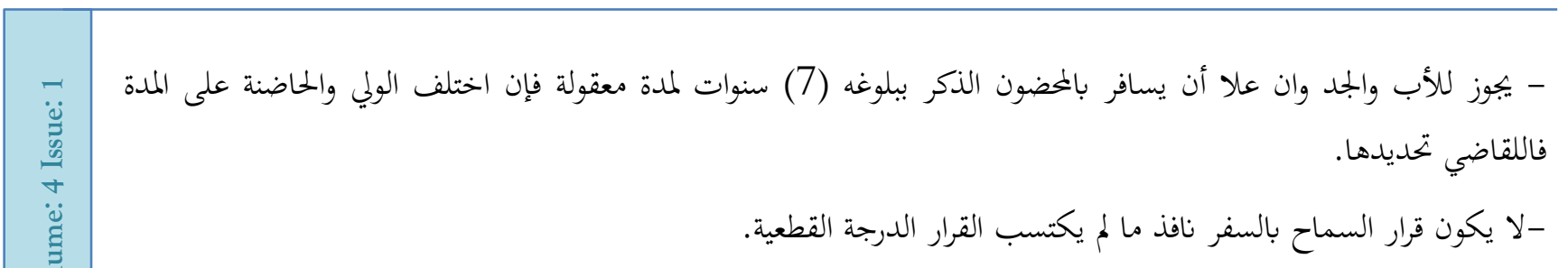




\section{المصادر}

ابراهيم بن علي بن يوسف الشيرازي. (1992). المهذب في فقه الأمام الشافعي. دمشق-بيروت: دار القلم-الدار الشامية.

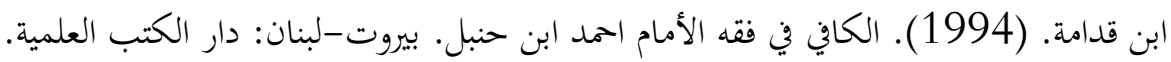

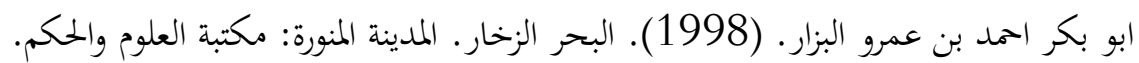
ابو بكر الرازي. (1950). غختار الصحاح. بولاق-مصر : المطبعة المبعة الأميرية. ابي عمر يوسف القرطبي. (1978). الكافي في فقه اهل المدينة. الرياض: مكتبة الرياض الحديثة. الدسوقي. (دون ذكر سنة النشر). حاشية الدسوقي على الشرح الكبير ج2. مصر : مطبعة عيسى البابي الحلبي.

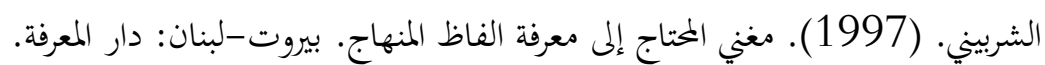

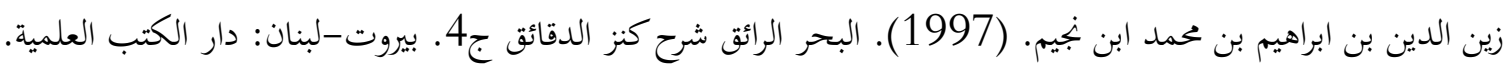

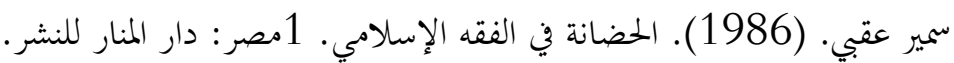

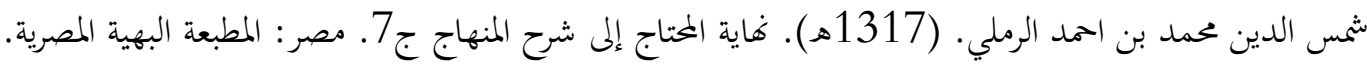
عبد الستار حامد. (1986). أحكام الاسرة في الفقه الإسلامي. بغداد: مطبعة الجامعة. عبدالله بن محمد ابن قدامة. (1997). المغني. الرياض: دار عالم الكتاب. لإناب. فخر الدين عثمان بن علي الزيلعي. (1314هـ). تبيين الحقائق شرح كنز الدقائق. بولاق: المطبعة الأميرية الكبرى.

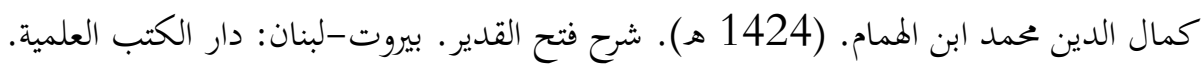

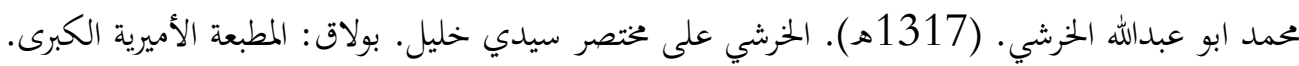

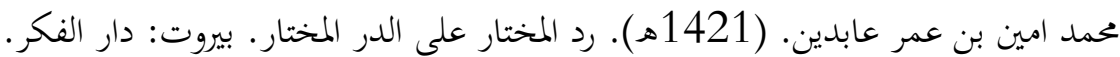

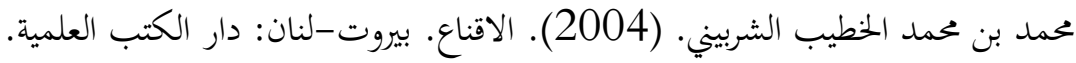

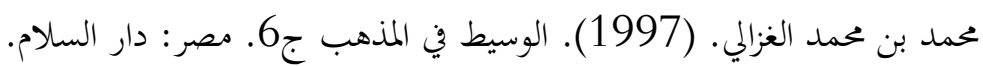

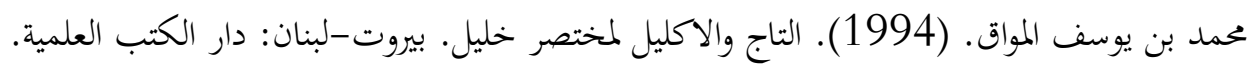
محمد حسن كشكول، عباس السعدي. (2011). شرح قانون الأحوال الشخصية. المكتبة القانونية: بغداد. لماد.

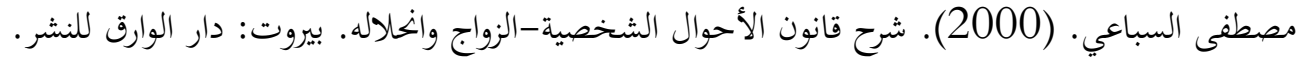

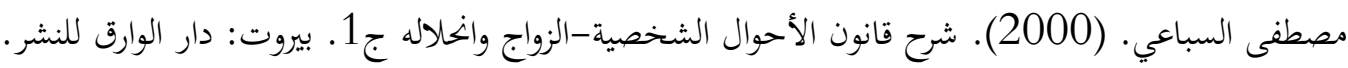

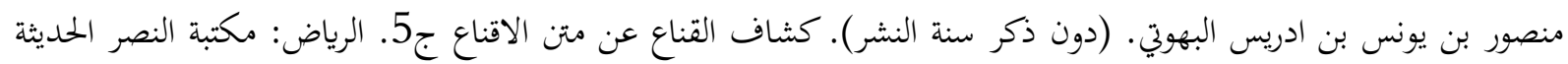
للنشر.

يهيى بن ابي الخير بن سالم العمراني. (دون ذكر سنة النشر). البيان في مذهب الأمام الشافعي. دون ذكر بلد النشر: دار المنهاج. 